\title{
Ribosomal protein S27-like is a physiological regulator of p53 that suppresses genomic instability and tumorigenesis
}

\author{
Xiufang Xiong ${ }^{1 \dagger}$, Yongchao Zhao ${ }^{1 \dagger}$, Fei Tang ${ }^{2}$, Dongping Wei ${ }^{1}$, Daffyd Thomas ${ }^{3,4}$, \\ Xiang Wang ${ }^{1}$, Yang Liu ${ }^{2}$, Pan Zheng ${ }^{2}$, Yi Sun ${ }^{1,5 *}$ \\ 'Division of Radiation and Cancer Biology, Department of Radiation Oncology, \\ University of Michigan, Ann Arbor, United States; ${ }^{2}$ Center for Cancer and \\ Immunology Research, Children's National Medical Center, Washington, United \\ States; ${ }^{3}$ Department of Pathology, University of Michigan Medical School, Ann \\ Arbor, United States; ${ }^{4}$ Comprehensive Cancer Center, University of Michigan \\ Medical School, Ann Arbor, United States; ${ }^{5}$ Institute of Translational Medicine, \\ Zhejiang University School of Medicine, Hangzhou, China
}

*For correspondence: sunyi@ umich.edu

TThese authors contributed equally to this work

Competing interests: The authors declare that no competing interests exist.

Funding: See page 25

Received: 08 January 2014 Accepted: 20 August 2014 Published: 21 August 2014

Reviewing editor: Carol Prives, Columbia University, United States

(c) Copyright Xiong et al. This article is distributed under the terms of the Creative Commons Attribution License, which permits unrestricted use and redistribution provided that the original author and source are credited.

\begin{abstract}
Cell-based studies showed that several Mdm2-binding ribosomal proteins, upon overexpression, stabilize and activate p53. In contrast, here we show in a mouse knockout study that Mdm2-binding ribosomal protein S27-like (Rps27l), upon disruption, activates p53. Germline inactivation of Rps27/ triggers ribosomal stress to stabilize Mdm2, which degrades Mdm4 to reduce Mdm2-Mdm4 E3 ligase towards p53, leading to p53-dependent apoptotic depletion of hematopoietic stem cells and postnatal death, which is rescued by Trp53 deletion. Paradoxically,

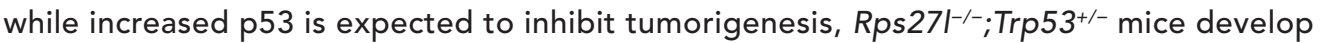
lymphomas at higher incidence with p53 loss-of-heterozygosity and severe genome aneuploidy, suggesting that Rps27l disruption impose a selection pressure against p53. Thus, Rps27l has dual functions in p53 regulation: under Trp53 $3^{+/}$background, Rps27l disruption triggers ribosomal stress to induce p53 and apoptosis, whereas under Trp53+/- background, Rps27l disruption triggers genomic instability and Trp53 deletion to promote tumorigenesis. Our study provides a new paradigm of $\mathrm{p} 53$ regulation. DOI: 10.7554/eLife.02236.001
\end{abstract}

\section{Introduction}

Tumor suppressor p53 is a key regulator of cell growth and cell death (Ko and Prives, 1996; Levine, 1997) and is activated by many environmental stimuli, including DNA damaging agents (Giaccia and Kastan, 1998). Activated p53 acts as a guardian of the genome by inducing growth arrest, allowing cells to repair the damage, or apoptosis when the damage is too severe and irreparable (Vogelstein et al., 2000; Levine and Oren, 2009). p53 is frequently inactivated during human carcinogenesis either by point mutation which occurs in $50 \%$ of human cancers (Greenblatt et al., 1994), or by Mdm2/ Mdm4-mediated ubiquitylation and degradation (Kruse and Gu, 2009; Wade et al., 2013).

Mdm2 is a direct p53 target. Upon induction by p53, Mdm2 inactivates p53 through at least two main mechanisms: (a) binding to p53 at its transactivation domain and blocking its transactivation activity, and (b) serving as an E3 ubiquitin ligase to promote a rapid degradation of p53 (Haupt et al., 1997; Honda et al., 1997; Kubbutat et al., 1997; Fang et al., 2000; Honda and Yasuda, 2000). Thus, p53-Mdm2 forms an auto-regulatory feedback loop to keep p53 levels under control (Wu et al., 1993). Both in vitro and in vivo studies indicated that oncogenic activity of Mdm2 is mainly attributable to its binding to and degrading p53 (Jones et al., 1995; Montes de Oca Luna et al., 1995; 
eLife digest There are over a hundred different types of cancer that can affect humans; but, in general, all cancers are caused by mutations that cause cells to grow and divide abnormally. 'Tumor suppressor genes' are genes that normally protect a cell from genetic changes that can lead a cell towards becoming cancerous.

About half of all cancers in humans have a mutation in one of the two copies of a tumor suppressor gene that encodes a protein called p53, which helps to control how and when cells grow and divide. In normal cells, the p53 protein can be activated in various ways. Damage to a cell's DNA triggers p53 to stop the cell growing, which gives the cell time to repair the DNA damage. However, if the damage is too severe and cannot be repaired, p53 essentially causes the cell to kill itself, via a process called apoptosis. Furthermore, if a cell has problems building new copies of its protein-making machinery, some of the parts (called ribosomal proteins) that make up these molecular machines can also lead to $p 53$ being activated.

By deleting the gene for a protein called Rps27l that is a newly characterized ribosomal protein, Xiong et al. have discovered that, in mice, Rps27l regulates the p53 protein in two different ways. In normal cells, Rps27l appears to inhibit p53, which is likely to encourage cancer to develop. But, if a cell has already lost a copy of the p53 gene-a situation that would normally encourage the cells to accrue further mutations and become cancerous-Rps27l acts as a tumor suppressor. In these mutated cells, the Rps27I protein helps to maintain the stability of the genome and prevent the loss of the second copy of gene for p53, and so protects the cell from becoming cancerous.

Thus Rps27I can either activate or inactivate p53 activity depending on how many copies of the gene for p53 remain intact. The next challenge is to investigate if Rps27l levels determine the early-onset of tumor development in cancer-prone cells seen in patients with Li-Fraumeni syndrome, who are born with a mutated copy of the p53 gene.

DOI: 10.7554/eLife.02236.002

de Rozieres et al., 2000). The key role of Mdm2 E3 ligase activity in controlling p53 levels in a physiological setting was further demonstrated by a knock-in study in which introduction of a ligase dead $M d m 2^{\text {C462A }}$ mutant results in embryonic lethality, that like Mdm2 deletion, can be fully rescued by simultaneous Trp53 deletion (Itahana et al., 2007).

In addition to Mdm2, p53 is also subject to negative regulation by Mdm4 (also known as MdmX), an Mdm2 family member (Shvarts et al., 1996). Although Mdm4 itself does not have an intrinsic E3 ligase activity toward p53 (Linares et al., 2003), it does bind to p53 transactivation domain to block its transcription activity (Shvarts et al., 1996). Moreover, Mdm4 forms a tight 1:1 complex with Mdm2 via their respective C-terminal RING finger domains (Sharp et al., 1999; Tanimura et al., 1999), and the Mdm2-Mdm4 heterodimers are the preferred dimer form, compared to the Mdm2-Mdm2 or Mdm4-Mdm4 homodimers (Kostic et al., 2006). Furthermore, Mdm4 is a direct substrate of Mdm2 for targeted ubiquitylation and degradation (de Graaf et al., 2003; Kawai et al., 2003; Pan and Chen, 2003). More importantly, both in vitro cell culture studies using Mdm2 mutants (Kawai et al., 2007; Poyurovsky et al., 2007; Uldrijan et al., 2007) and in vivo studies using knock-in mice of Mdm2 and Mdm4 mutants (Itahana et al., 2007; Huang et al., 2011; Pant et al., 2011; Wang et al., 2011) demonstrated that the Mdm2-Mdm4 heterodimer has an optimal E3 ligase activity and is required for p53 degradation. Thus, the Mdm2-Mdm4 complex is interconnected and crossregulated to keep p53 levels precisely in check under physiological conditions (such as during embryogenesis) and in response to various stresses (Wade et al., 2013).

Accumulated biochemical and cellular studies have shown that the p53-MDM2-MDM4 axis is further regulated by various ribosomal proteins (Zhang and Lu, 2009). Specifically, the ribosomal proteins, such as RPL11 (Lohrum et al., 2003; Zhang et al., 2003; Bhat et al., 2004; Sasaki et al., 2011), RPL5 (Dai and Lu, 2004), RPL23 (Dai et al., 2004; Jin et al., 2004), RPL26 (Zhang et al., 2010), RPS7 (Chen et al., 2007; Zhu et al., 2009), RPS3 (Yadavilli et al., 2009), RPS27/S27L (Xiong et al., 2011), S27a (Sun et al., 2011), RPS25 (Zhang et al., 2013), RPS26 (Cui et al., 2014) and RPS14 (Zhou et al., 2013), as well as RPL37, RPS15 and RPS20 (Daftuar et al., 2013), were found to bind to MDM2 upon ribosomal stress and inhibit MDM2-mediated p53 ubiquitylation and degradation, leading to p53 activation to induce growth arrest and apoptosis, thus acting as p53 activators (Zhang and Lu, 2009). 
However, whether and how these Mdm2-binding ribosomal proteins indeed regulate $\mathrm{p} 53$ by modulating $\mathrm{Mdm} 2$ activity has not been explored previously using an in vivo mouse model.

RPS27L (NM_015920) is an 84-amino acid ribosomal like protein, which differs from its family member RPS27 (NM_001030) by only three amino acids (R5K, L12P, K17R) at the N-terminus. We and the others found that RPS27L is a direct p53 inducible target (He and Sun, 2007; Li et al., 2007). Our recent cell-based study showed that RPS27L directly binds to MDM2 and is subjected to MDM2-mediated ubiquitylation and degradation (Xiong et al., 2011). Furthermore, RPS27L competes with p53 for MDM2 binding, consequently inhibiting MDM2-mediated p53 ubiquitylation and degradation (Xiong et al., 2011). Thus, RPS27L interplays with the MDM2-p53 axis to regulate p53 activity. Although several ribosomal proteins have been previously shown to bind and inhibit MDM2, causing p53 activation (Zhang and Lu, 2009), with RPS7 and RPL26 being MDM2 substrates as well (Ofir-Rosenfeld et al., 2008; Zhu et al., 2009), RPS27L is the first and only known ribosomallike protein that is a direct p53 inducible target, a MDM2 substrate, and a regulator of the MDM2-p53 axis. However, the physiological function of Rps27l and whether Rps27I plays a physiological role in regulation of the p53-Mdm2-Mdm4 axis in mouse remain entirely unknown.

Here we present in vivo evidence that, unlike in vitro cell culture studies which showed that several Mdm2-binding ribosomal proteins act as p53 activators, Rps27l, under the Trp53+/+ background, appears to be a physiological p53 inhibitor that stabilizes the Mdm2-Mdm4 heterodimer for effective p53 ubiquitylation and degradation. Unexpectedly, we also found that Rps27l, under the Trp53+/background, acts as a tumor suppressor by maintaining the genomic integrity to prevent the loss of Trp53 heterozygosity and subsequent development of lymphoma. Thus, Rps27l regulates p53 either negatively or positively in a manner dependent of Trp53 dosage.

\section{Results}

\section{Rps27l disruption causes postnatal death as a result of increased apoptosis}

Our previous studies showed that RPS27L is a direct p53 target (He and Sun, 2007) and regulates p53 activity by interacting with MDM2 (Xiong et al., 2011). To test the physiological function of Rps27l, we generated the gene-trap based Rps27/+/- mice through Texas Institute for Genomic Medicine (TIGM) in a pure C57BL/6 background from an ES clone, IST11658B7, with a targeted BGEO vector inserted at the intron 1 to disrupt the open reading frame of Rps27l (Figure 1-figure supplement 1A). Intercrossing of Rps27/+- mice gave rise to the $\mathrm{F} 1$ offspring with three Rps27l genotypes, as confirmed by Southern blotting, PCR genotyping, and immunoblotting (Figure 1-figure supplement 1B-D). Thus, Rps27l deletion is not embryonic lethal. However, genotyping of 351 offspring at weaning of the

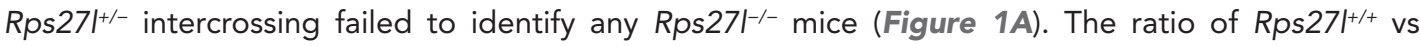
Rps27/+- mice was about 1:2, indicating that Rps27l mutation is homozygous lethal (Figure 1A). In fact, all Rps271/-- pups in a pure C57BL/6 background died within 12 days of birth. Under a mixed sv129/B6 background, about $50 \%$ mice die at 18 day after birth with the longest life-span of 35 days (Figure 1figure supplement 1E). Thus, Rps27/ disruption causes postnatal death.

Compared to the wild type and heterozygous littermates, $R p s 271^{-1-}$ mice were about $50 \%$ in size and body weight (Figure 1B,C). At the organ levels after normalization with the body weight, the weight in the thymus and spleen was significantly reduced in Rps27//- mice at P8-10 (Figure 1D). The H\&E staining revealed that the bone marrow derived from Rps27/-- mice have much reduced cellularity (Figure 1E). Likewise, the Rps27/-- thymus showed a remarkable reduction in the thymic cortex, and thymocytes in cortical and cortical-medullary junction areas undergo apoptosis with accumulation of small irregular nuclear fragments (Figure 1F, arrows). Induction of apoptosis was further confirmed by the immunofluorenscent staining with antibody against cleaved caspase- 3 in both thymocytes (Figure 1G) and bone marrow cells (Figure 1H). Moreover, apoptosis in thymus was readily detectable by immunoblotting, which showed increased levels of cleaved caspase-3 and pro-apoptotic protein Puma (Figure 11). An increased apoptosis, as reflected by Annexin V staining (Figure 1J, Figure 1figure supplement 1F), but not reduced proliferation, as reflected by BrdU incorporation (Figure 1figure supplement 1G) was also seen in myeloid progenitors (MP), derived from E14.5 Rps27/-1fetal livers. Finally, hypo-cellularity of bone marrow, thymus, and spleen was readily observed in Rps27//- mice with a mixed 129/B6 background (Figure 1-figure supplement 1H,I). Thus, Rps27I is required for postnatal development of some organs, particularly thymus, spleen and bone marrow, 
A

Rps27/ knockout causes postnatal death

\begin{tabular}{|c|c|c|c|c|}
\hline & Rps271 ${ }^{+/}$ & $R p s 271^{+/}$ & $R p s 271^{-/}$ & Total \\
\hline No. of mice (>3wks) & 119 & 232 & 0 & 351 \\
\hline Expected ratio & $1 / 4$ & $1 / 2$ & $1 / 4$ & \\
\hline
\end{tabular}

B

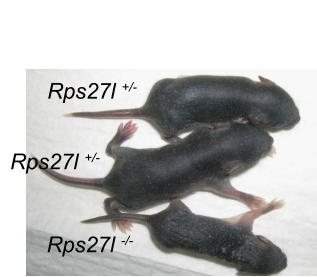

$\mathbf{E}$

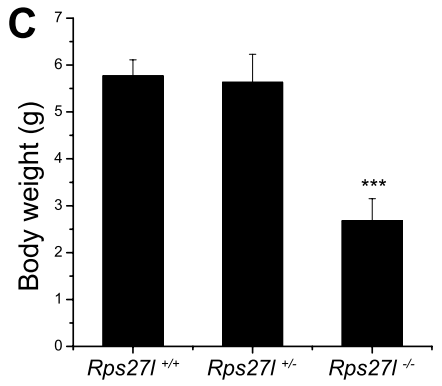

D

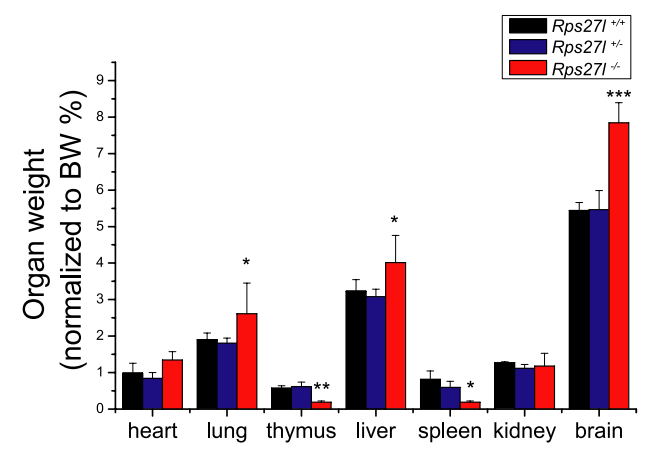

G
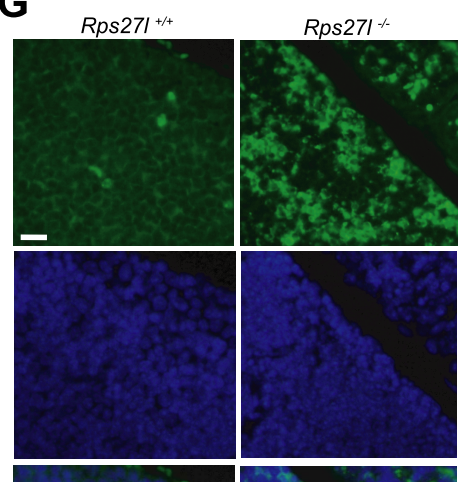

Cleaved

caspase-3

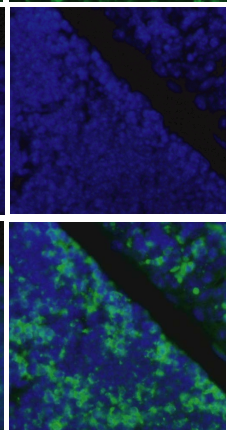

DAPI
F

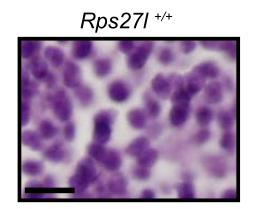

H
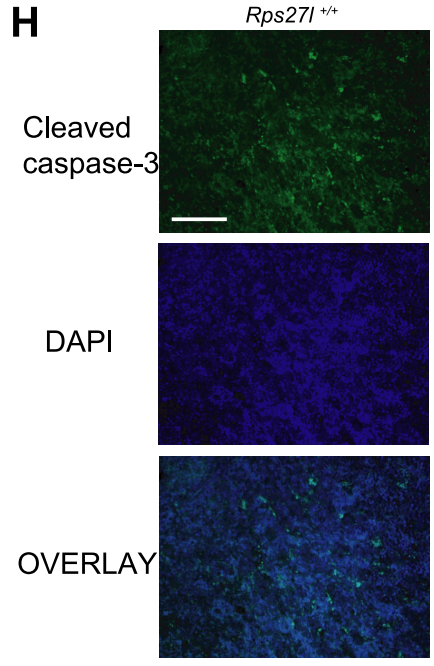

Rps271 -

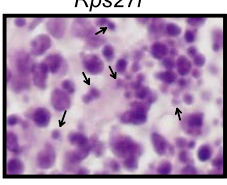

Rps $271 \%$
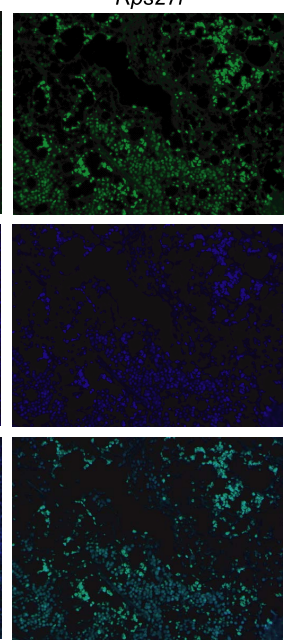

OVERLAY

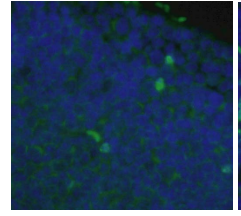

Thymus (P6)

I
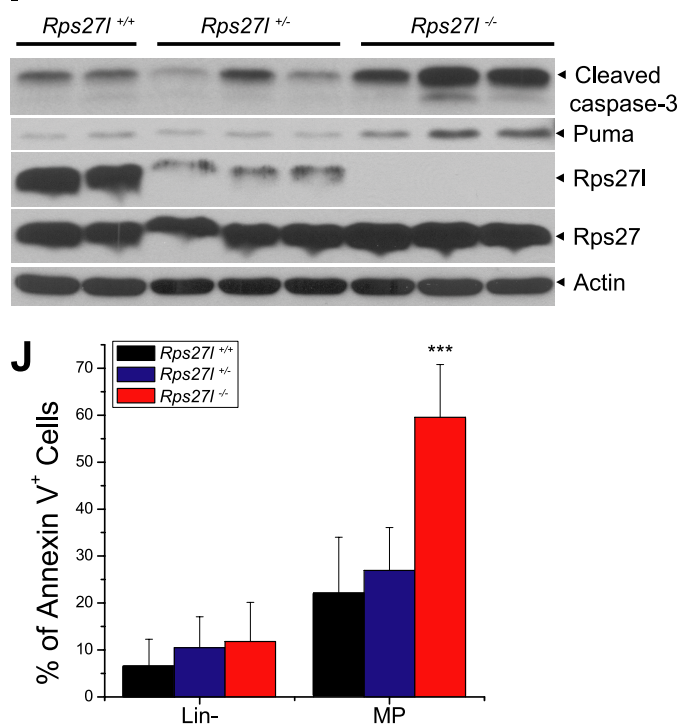

Figure 1. Rps27l disruption causes postnatal death as a result of increased apoptosis. (A) Disruption of Rps27/ causes postnatal death. (B-D) Reduced

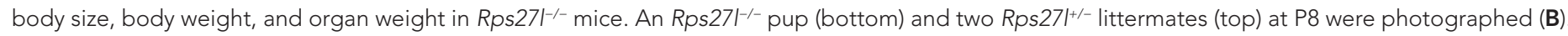

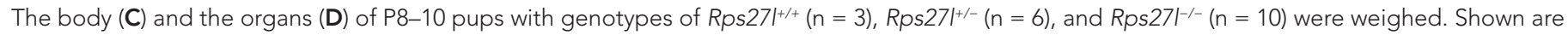
Figure 1. Continued on next page 
Figure 1. Continued

mean \pm SD. ${ }^{*} p<0.05,{ }^{* *} p<0.01$, and ${ }^{* \star *} p<0.001$, as compared to Rps $271^{+/+}$counterparts. (E) Representative H\&E staining of bone marrows in femurs of P6 pups. Scale bars represent $200 \mu \mathrm{m}$ (top) and $40 \mu \mathrm{m}$ (bottom). (F) Representative H\&E staining of thymuses from P8-10 pups. Arrows point to apoptotic cells. Scale bar represents $10 \mu \mathrm{m}$. (G and $\mathbf{H})$ Representative immunofluoresent staining of cleaved caspase-3 in thymuses (G) of P8-10 pups and bone marrows $(\mathbf{H})$ of P6 pups. Scale bars represent $20 \mu \mathrm{m}(\mathbf{G})$ and $100 \mu \mathrm{m}(\mathbf{H})$. (I) Accumulation of cleaved caspase-3 and Puma in Rps27/-/- thymuses. The thymuses of P6 pups were lysed for immunoblotting (IB). (J) Increased Annexin V-positive myeloid progenitors (MP) in Rps27/-1- fetal livers. Cells

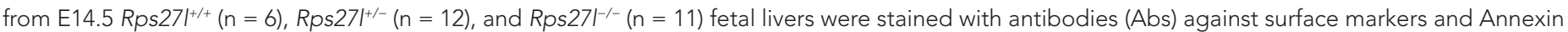
V-FITC, followed by FACS analysis. Data shown are mean \pm SD. ${ }^{\star \star *} p<0.001$, as compared to Rps $277^{+++}$counterparts.

DOI: 10.7554 /eLife.02236.003

The following figure supplement is available for figure 1:

Figure supplement 1. Generation of Rps27l gene trap mice and phenotypes of Rps27//- mice. DOI: 10.7554/eLife.02236.004

and postnatal death of Rps 27 l knockout mice is likely associated with enhanced apoptosis, leading to bone marrow depletion.

\section{Rps27l disruption causes the loss of hematopoietic stem and progenitor cells in fetal liver}

To determine potential sources of bone marrow depletion in Rps271-/- pups, we compared the fetal livers from E14.5 embryos among three Rps27/ genotypes and found that Rps27//- fetal livers are visibly smaller with significant reduction in cell number (Figure 2A,B). The FACS analysis of Rps27/ ${ }^{-1-}$ fetal livers revealed a substantial reduction in number of hematopoietic stem and progenitor cells (HSPCs), including hematopoietic stem cells (HSCs)-containing LSK ( $\left.\mathrm{Lin}^{-} / \mathrm{Sca}-1^{+} / \mathrm{c}-\mathrm{Kit}^{+}\right)$population, and MP population, consisting of common myeloid progenitor (CMP), granulocyte-monocyte progenitor (GMP), and megakaryocytic-erythroid progenitor (MEP) cells (Figure 2C-F, Figure 2-figure supplement 1A). To determine the viability and functionality of Rps27//- HSPCs, we performed a noncompetitive reconstitution assay to see whether these stem cells, while reduced in number, are still sufficient to rescue the bone marrow failure of recipient mice which were sterilized by a lethal dose of radiation. A total of $2 \times 10^{6}$ fetal liver cells from either Rps $27 \mathrm{I}^{+/+}$or $R p s 27 \mathrm{I}^{-/-}$embryos were used. Remarkably, while HSPCs from wild type fetal liver cells completely reconstituted sterilized bone marrow and fully rescued the recipient mice, cells from Rps27/ $\mathrm{I}^{-1-}$ fetal livers were unable to do so, leading to a $100 \%$ death of recipient mice within 10 days of reconstitution (Figure $2 \mathbf{G}, \mathbf{H}$, Figure 2-figure supplement $1 \mathrm{~B}$ ). To eliminate possibility that the failure in rescue is due to an insufficient number of stem cells in Rps $27 \mathrm{I}^{-/-}$fetal livers, which is about $50 \%$ of the Rps $27 \mathrm{I}^{+/+}$control (Figure $2 C, 0.005 \%$ vs $0.01 \%$ of total liver), we repeated this non-competitive reconstitution assay, using three times more fetal liver cells $\left(6 \times 10^{6}\right)$ from the Rps27/ ${ }^{-1-}$ embryos than that $\left(2 \times 10^{6}\right)$ from the Rps $27 I^{+/+}$or Rps $27 I^{+/-}$embryos. Again, the stem cells from $R p s 27 I^{-/-}$fetal livers failed to rescue sterilized recipient mice with $100 \%$ death within 12 days post reconstitution, whereas those from wild type or heterozygous fetal liver caused a 100\% rescue (Figure 2-figure supplement 1C), indicating an intrinsic defect. Peripheral blood profiling of rescued mice showed a normal distribution of various blood cells (Figure 2-figure supplement 1D,E).

To further confirm the inability of stem/progenitor cells from Rps27/-- fetal livers in re-building the recipient bone marrow, we performed a competitive reconstitution assay in which a 1:4 mixture of recipient bone marrow cells with donor fetal liver cells derived from $R p s 27 I^{+++}$vs $R p s 27 I^{-/-}$embryos was given to sterilized recipient mice (Figure 21). In this case, all recipient mice survived, as expected. Bone marrow profiling of surviving chimeric mice at 4,12 and 20 weeks post reconstitution revealed that while $65-85 \%$ cells were derived from the $R p s 271^{+/+}$donor fetal livers, none of cells were derived from $R p s 27 I^{-1}$ donor fetal livers (Figure $2 \mathrm{~J}, \mathrm{~K}$ ). Together, our study clearly demonstrated in vivo that HSPCs from $\left.R p s 27\right|^{-1-}$ fetal livers must gradually die or fail to repopulate sterilized bone marrow. Thus, defective hematopoiesis is most likely contributable to postnatal lethality of Rps271/-- mice.

\section{Rps27l disruption increases p53 level}

We next investigated potential mechanisms by which Rps27l disruption induces apoptosis and causes the loss of HSPCs and depletion of bone marrow. We focused on p53, since (1) our recent study showed that RPS27L could modulate MDM2 to regulate the level and activity of p53 (Xiong et al.,

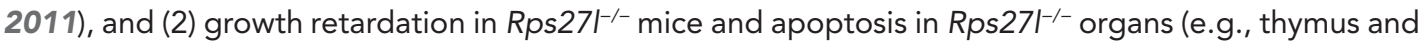




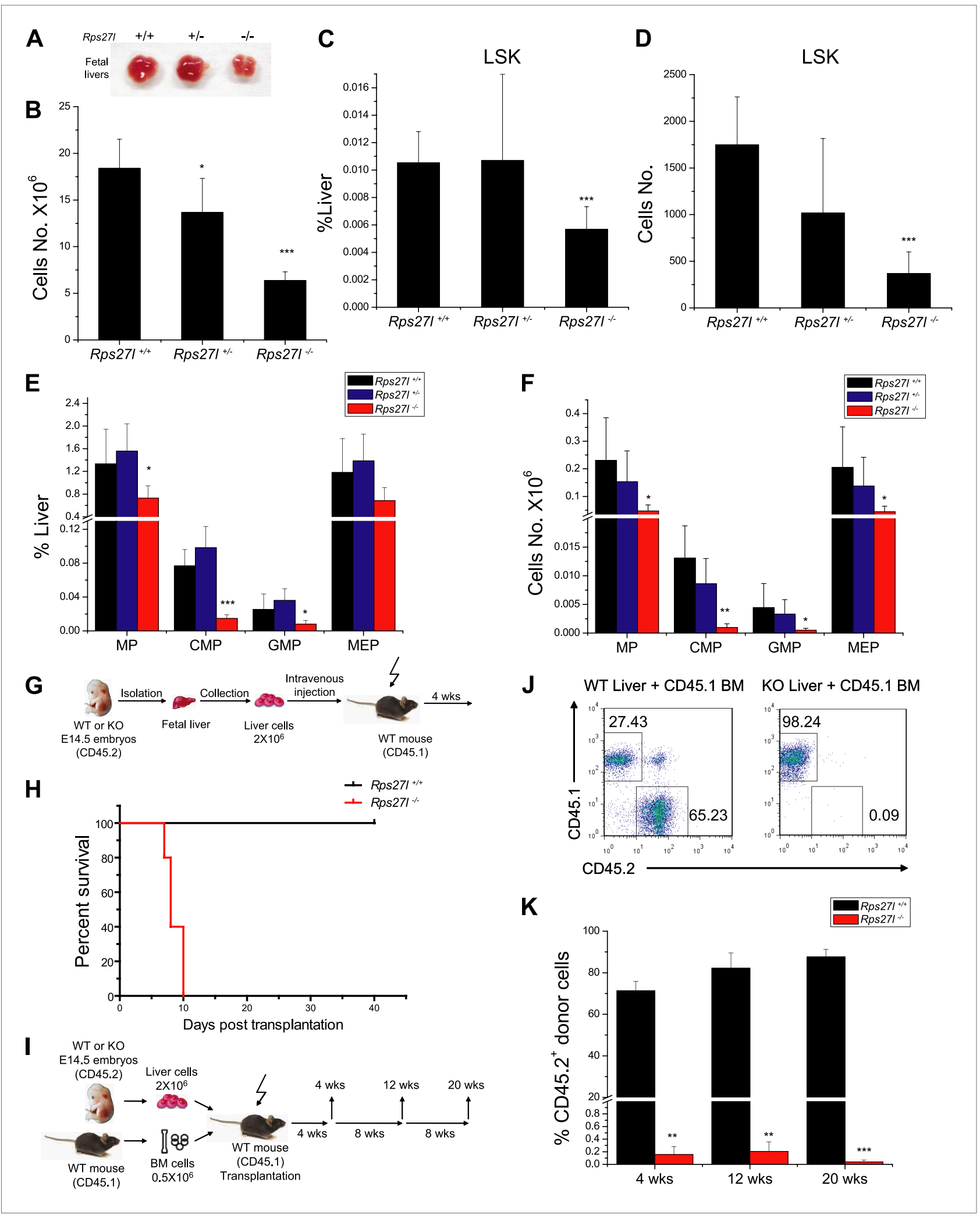

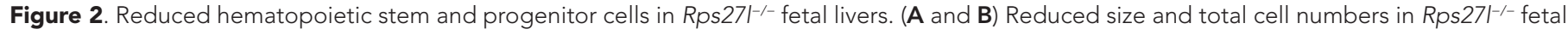
livers. Representative fetal livers of three genotypes were photographed (A), and the numbers of fetal liver cells from E14.5 embryos were counted.

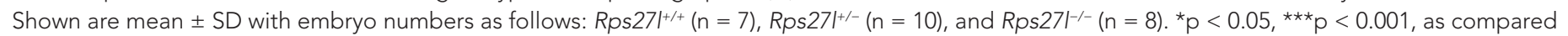

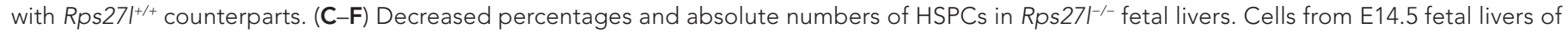
Figure 2. Continued on next page 
Figure 2. Continued

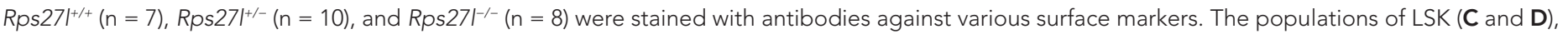
MP, CMP, GMP, and MEP (E and F) were analyzed by flow cytometry. Shown are mean \pm SD. ${ }^{\star} p<0.05$, ** $p<0.01$, and ${ }^{* \star *} p<0.001$, as compared with Rps $271^{+/+}$counterparts. (G) Diagram of non-competitive reconstitution assay. Fetal liver cells $\left(2 \times 10^{6}\right.$ cells) from E14.5 embryos (CD45.2) were injected into lethally irradiated recipient mice (CD45.1). Peripheral blood from recipients was analyzed by flow cytometry at 4 weeks after transplantation.

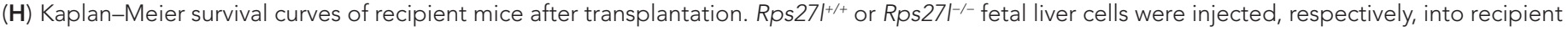
mice $\left(n=5\right.$, for each genotype). $p=0.0026$. (I) Diagram of competitive reconstitution assay. Fetal liver cells $\left(2 \times 10^{6}\right.$ cells) from E14.5 embryos (CD45.2) were injected into lethally irradiated recipient mice (CD45.1) together with bone marrow cells $\left(0.5 \times 10^{6}\right.$ cells) from normal recipient mice. Peripheral blood from recipients was analyzed by flow cytometry at 4, 12, and 20 weeks after transplantation. (J) Representative FACS profiles of donor-type (CD45.2) and recipient-type (CD45.1) blood cells at 4 weeks post transplantation. (K) Dramatic reduction of donor-type (CD45.2) blood cells in recipients transplanted with Rps27/ $1^{-1}$ fetal livers. The percentages of CD45.2+ cells in peripheral blood at 4, 12, and 20 weeks post transplantation were summa-

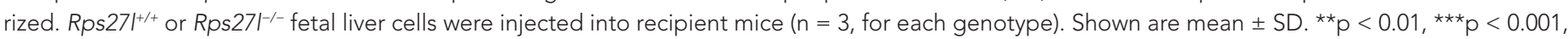
as compared to Rps27/+/+ counterparts.

DOI: 10.7554 /eLife.02236.005

The following figure supplement is available for figure 2:

Figure supplement 1. Depletion of hematopoietic stem and progenitor cells (HSPCs) upon Rps27l disruption. DOI: 10.7554/eLife.02236.006

bone marrow) are the typical phenotypes of p53 activation. Indeed, by immunohistochemistry analysis, we detected more p53 positively stained cells in the fetal livers and bone marrows derived from

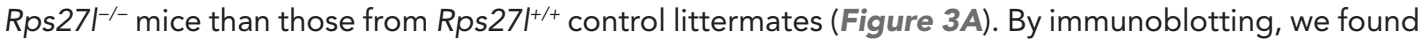
that both basal and radiation-induced levels of p53 and p53 target protein Puma are higher in fetal

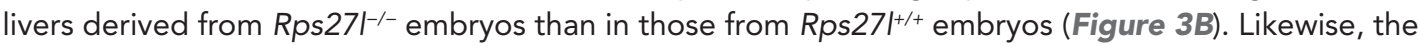

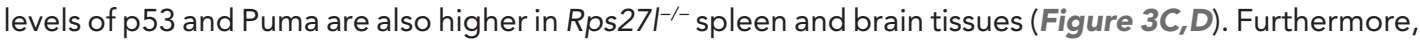
we observed a moderate increase in the levels of p53 and its two well-known targets, Mdm2 and p21 in MEFs derived from Rps27/ ${ }^{-/-}$embryos than in those from Rps27//+ embryos (Figure 3E). Finally, the p53 levels, induced by (a) ribosomal stress inducer, actinomycin D (Act D), (b) DNA damaging agent, etoposide (Figure 3-figure supplement 1A), or (c) ionizing radiation (Figure 3-figure supplement 1B),

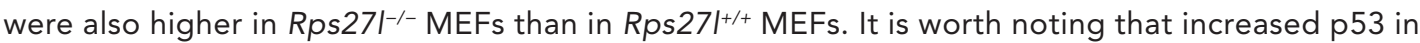
Rps271/- MEFs is unlikely due to enhanced DNA damage response, given the similar phosphorylation levels of $\mathrm{yH} 2 \mathrm{AX}$ and Chk1 between MEFs of the two genotypes (Figure 3-figure supplement 1B). Taken together, our results clearly showed that Rps27l disruption causes an increase in p53 levels in multiple organs and cell types, and that increased p53 is transcriptionally active to induce the expression of its downstream targets, namely p21, Mdm2 and Puma.

\section{Increased p53 level upon Rps27I disruption is due to reduced p53 ubiquitylation and degradation}

We next determined the mechanism by which Rps27l disruption causes p53 increase. Quantitative RT-PCR analysis using four independent sets of MEFs revealed that Rps27l disruption did not increase p53 mRNA level, but as expected, increased mRNA levels of two p53 targets, Mdm2 and p21, due to p53 transactivation (Figure 4-figure supplement 1A). The $\left[{ }^{35} \mathrm{~S}\right]$-methionine labeling experiment in two independent pairs of MEFs showed that the rate of p53 synthesis is similar regardless of Rps27I status (Figure 4-figure supplement 1B), indicating that Rps27l disruption does not alter the p53 protein synthesis. We then focused our attention on the rate of p53 degradation by measuring the p53 protein half-life. We found that p53 half-life was doubled from $\sim 10 \mathrm{~min}$ to $\sim 25 \mathrm{~min}$ in MEFs upon Rps27I disruption (Figure 4A) due to reduced ubiquitylation and degradation (Figure 4B, Figure 4figure supplement 1C). Because the major E3 ligase for p53 degradation is Mdm2, we performed an in vitro ubiquitylation assay, using, as the E3 source, the Mdm2 complex immuno-precipitated from the paired Rps27I MEFs, and found that the p53 ubiquitylation was reduced in Rps27/1- MEFs substantially (Figure 4C), indicating a reduced Mdm2 ligase activity toward p53.

\section{Rps27l disruption alters the levels and complex formation of Mdm2 and Mdm4}

We have shown that Rps27l disruption increases the levels of both Mdm2 mRNA (Figure 4-figure supplement 1A) and protein (Figure 3C-E). We then measured the Mdm2 protein half-life and

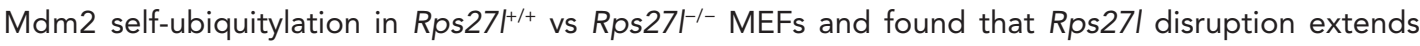
$\mathrm{Mdm} 2$ protein half-life from $18 \mathrm{~min}$ to $40 \mathrm{~min}$ (Figure $4 \mathrm{~A}$ ), which is likely attributable to a decreased 


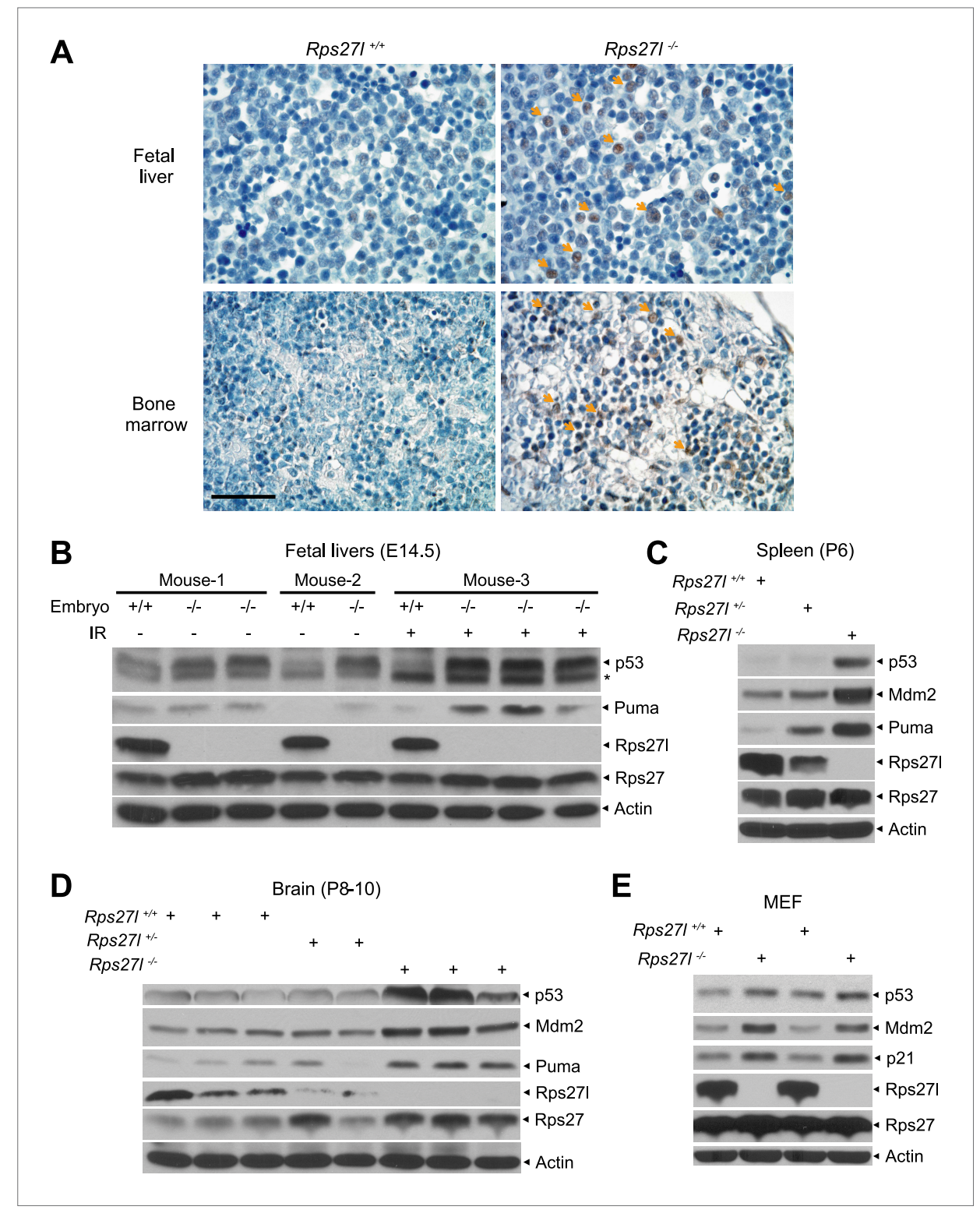

Figure 3. Rps27/ disruption causes a moderate increase of p53 and p53 targets. (A) Representative p53 staining in fetal livers and bone marrows. Fetal livers at E14.5 and bone marrows at P6 were immuno-stained with p53 Ab. Arrows point to $\mathrm{p} 53$ positive staining. Scale bar represents $40 \mu \mathrm{m}$. (B) Accumulation of p53 and Puma in

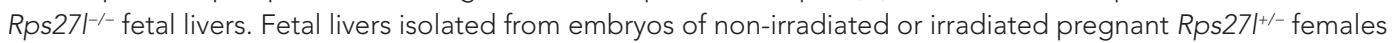
(E14.5) were lysed for IB at $5 \mathrm{hr}$ after ionizing radiation at $5 \mathrm{~Gy}$. * denotes a nonspecific band. (C) Accumulation of p53 and p53 targets in Rps27/-- spleens. Several spleens with the same genotype from P6 pups were harvested, pooled, homogenized, and subjected to IB. (D) Accumulation of p53 and p53 targets in Rps27//- brains. Brains from P8-10 pups were harvested and lysed for IB. (E) Accumulation of p53 and p53 target proteins in Rps27/ MEFs. Two independent pairs of MEFs from embryos at E13.5 were lysed for IB with indicated antibodies. DOI: 10.7554/eLife.02236.007

The following figure supplement is available for figure 3:

Figure supplement 1. Increased p53 levels in responsive to various stresses in Rps27/-- MEFs. DOI: 10.7554/eLife.02236.008

Mdm2 self-ubiquitylation (Figure 4D). We further used p53-null H1299 cells to determine this RPS27LMDM2 inverse relationship in a p53-independent manner. Consistently, we found that ectopic expression of RPS27L decreases MDM2 protein in a dose dependent manner, whereas RPS27L knockdown increases MDM2 protein (Figure 4E). Furthermore, ectopic RPS27L expression shortens the MDM2 
A
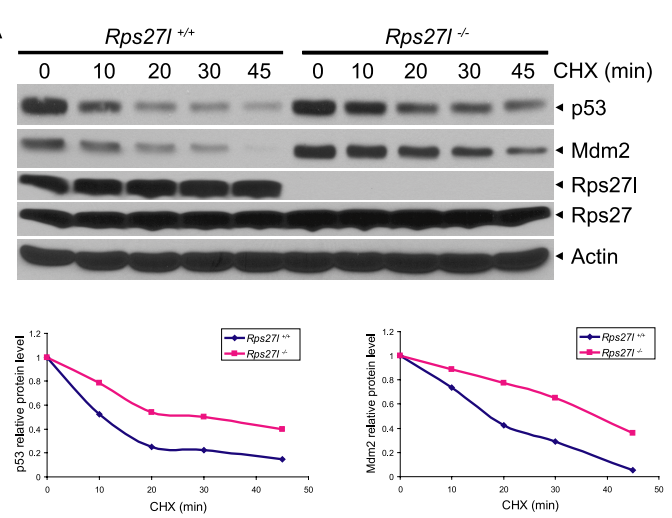

$\mathbf{E}$

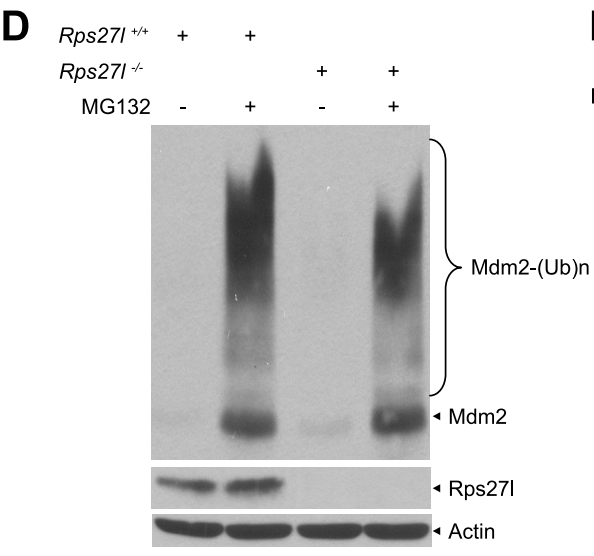

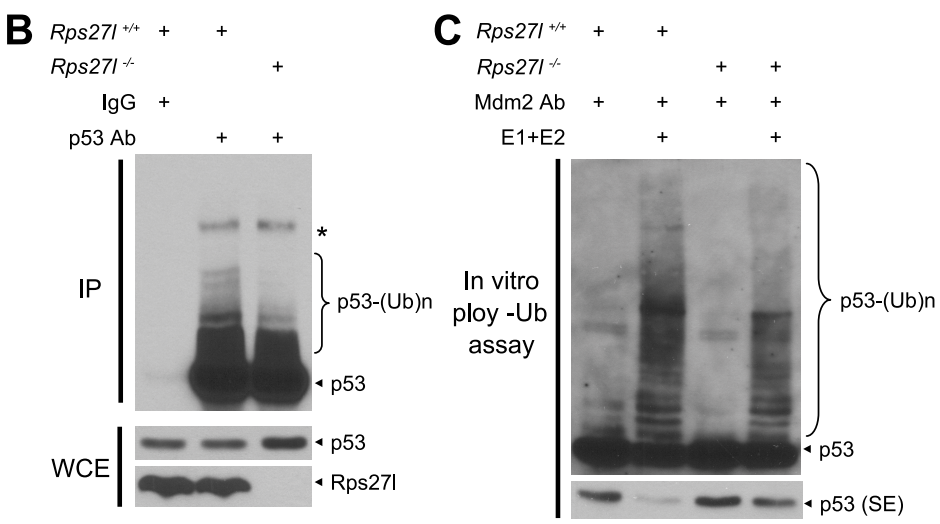

WCE

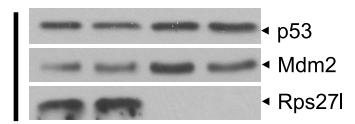

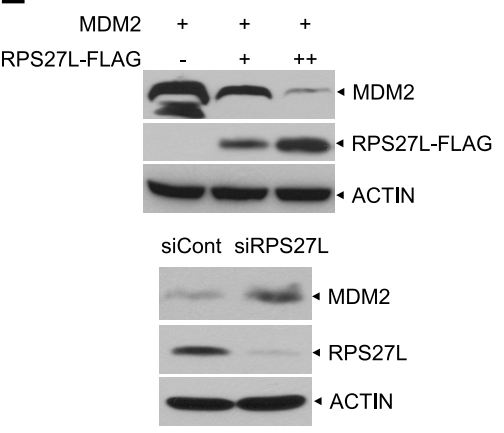

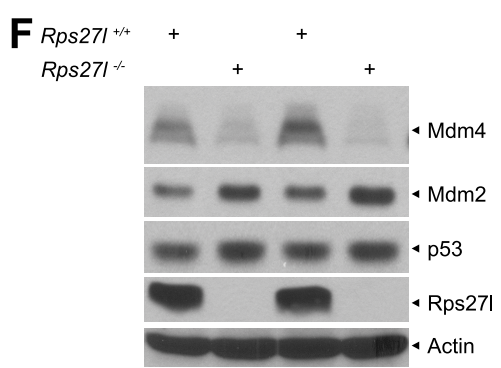

G

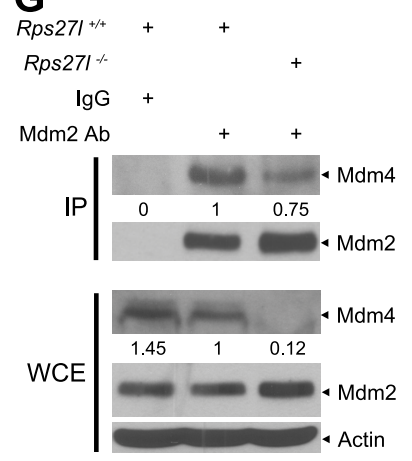

H

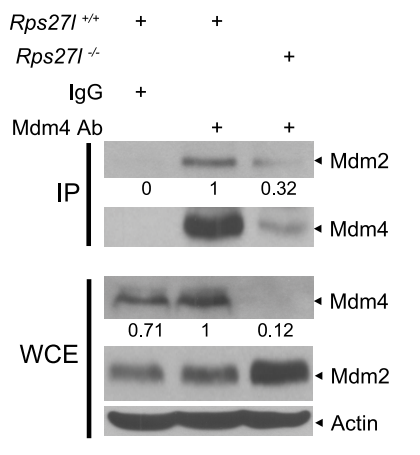

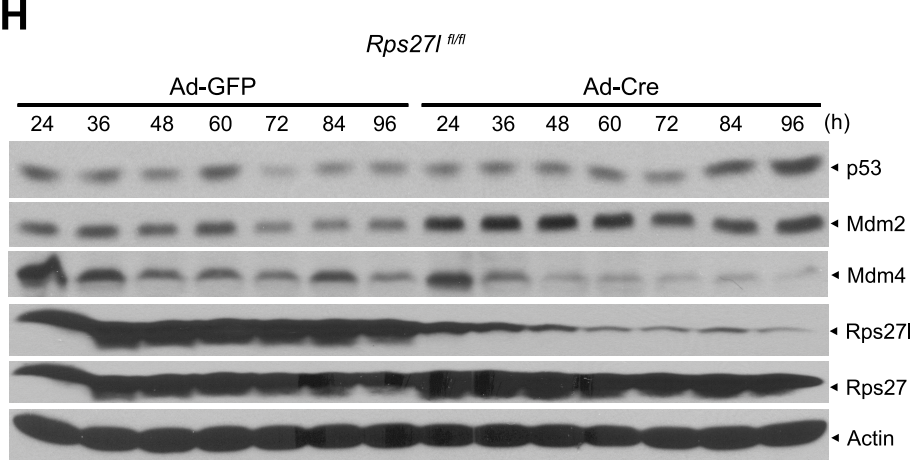

Figure 4. Rps27l disruption alters the levels of the p53-Mdm2-Mdm4 axis. (A) Extension of protein half-lives of p53 and Mdm2 upon Rps27l disruption. Rps $271^{+/+}$or Rps $271^{-1-}$ MEFs were harvested at various time points post $\mathrm{CHX}$ treatment for IB (top). Densitometry quantification was performed with ImageJ, and the decay curves are shown (bottom). (B) Rps27/ disruption impairs the ubiquitylation of endogenous p53 in vivo. Rps27/+/+ or Rps27/-/MEFs were harvested after $4 \mathrm{hr}$ of MG132 treatment for IP with p53 Ab or normal IgG control, followed by IB with p53 Ab (top), or for direct IB with p53 or Rps27l Ab (bottom). * denotes a nonspecific band. WCE: whole cell extract. (C) Rps27I disruption impairs p53 ubiquitylation in vitro. The Mdm2-Mdm4

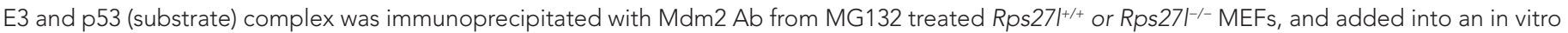
ubiquitylation reaction mixture containing ATP, ubiquitin, E1, and E2 (UbcH5b). After 60 min incubation with continuous vortexing, the reaction mixture was subjected to IB using p53 Ab. SE: short exposure. (D) Reduced Mdm2 self-ubiquitylation upon Rps27I depletion. Rps27/+/+ or Rps27///- MEFs were treated with MG132 for $4 \mathrm{hr}$ before being harvested for IB using indicated Abs. (E) Negative regulation of MDM2 protein levels by RPS27L. p53-null H1299 lung cancer cells were transfected with MDM2 alone, or in combination with two concentrations of FLAG-tagged RPS27L for 48 hr (top), or infected with lenti-virus targeting RPS27L or scrambled control siRNA for 3 days (bottom), followed by IB with indicated Abs. (F) Reduced Mdm4 protein level in Rps27//- MEFs. Two independent pairs of MEFs were harvested and subjected to IB with indicated Abs. (G) Reduced Mdm2-Mdm4

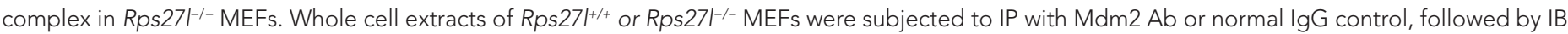
Figure 4. Continued on next page 
Figure 4. Continued

with Mdm4 Ab (left), or subjected to IP with Mdm4 Ab or normal IgG control, followed by IB with Mdm2 Ab (right). WCE were also subjected to direct IB with indicated Abs. Densitometry quantification was performed with ImageJ. (H) Sequential change in the protein levels of Mdm2, Mdm4, and p53 upon acute depletion of Rps27I. Rps27/f/f MEFs were harvested at various time points following adenoviral infection and subjected to IB.

DOI: 10.7554/eLife.02236.009

The following figure supplement is available for figure 4:

Figure supplement 1. Rps27l regulates p53 ubiquitylation and Mdm2 protein half-life. DOI: 10.7554/eLife.02236.010

protein half-life, while RPS27L knockdown extends it (Figure 4-figure supplement 1D). Thus, Rps27I disruption stabilizes $\mathrm{Mdm} 2$ by extending its protein half-life likely via reducing its self-ubiquitylation.

It appears paradoxical that an increased Mdm2 leads to a decreased p53 ubiquitylation and degradation. Given that Mdm2 is known to bind to its family member, Mdm4, to form the most active heterodimer E3 ligase toward p53 (Tanimura et al., 1999; Kostic et al., 2006; Kawai et al., 2007), we determined whether reduced Mdm2 E3 toward p53 upon Rps27I disruption is due to a reduced amount of Mdm4. Indeed, total cellular levels of Mdm4 were significantly reduced in several inde-

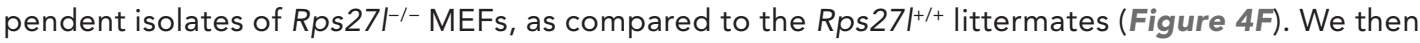
determined the binding affinity of $\mathrm{Mdm} 2$ and $\mathrm{Mdm} 4$ by the two-reciprocal immunoprecipitation (IP) assay in Rps27/ ${ }^{+/+}$vs Rps27/ ${ }^{-/-}$MEFs under unstressed native condition in the absence of proteasome inhibitor MG132. Although the total cellular level of Mdm4 was much lower in Rps27/-/- than in Rps27l+/+ MEFs with a ratio of 0.12 vs 1, the level of Mdm2-bound Mdm4 (pulled-down by Mdm2 IP) was much higher with a ratio of 0.75 vs 1 (Figure 4G, left). Reciprocally (Mdm4 IP), the level of Mdm4bound Mdm2 was also higher with a ratio of 0.32 vs 1 (Figure 4G, right). Thus, although a much lower total levels of Mdm4 in Rps27//- MEFs, most of Mdm4 molecules were found in the complex with Mdm2. These results clearly demonstrated that in the absence of Rps27l, Mdm2 actually has a higher binding affinity towards Mdm4, which might facilitate Mdm2-mediated Mdm4 degradation, leading to a decreased level of Mdm4, compromised Mdm2-Mdm4 ligase activity towards p53, and consequent p53 accumulation.

To elucidate the complicated interplays among p53-Mdm2-Mdm4-Rps27I, we generated Rps27/f/fl mice (unpublished data) and determined the initial and/or sequential event(s) that cause(s) the change in the Mdm2-Mdm4-p53 proteins upon acute depletion of Rps27l. Rps27ff/fl MEFs were infected with adenovirus expressing Cre recombinase (Ad-Cre) to deplete Rps27l. Compared to the Ad-GFP controls, acute depletion of Rps27l caused an elevated Mdm2, starting at $24 \mathrm{hr}$ post Ad-Cre infection and lasting up to $96 \mathrm{hr}$, followed by depletion of Mdm4, starting at $48 \mathrm{hr}$. A moderate accumulation of p53 was not seen until the later time points, starting at 72-84 hr following Ad-Cre infection (Figure 4H). Furthermore, Mdm2 accumulation, followed by Mdm4 reduction, is independent of p53, since a similar changing pattern was seen when Rps27/f/fl; Trp53-/- MEFs were infected with Ad-Cre (Figure 4figure supplement 1E). Taken together, these results clearly demonstrated that upon Rps27/ depletion (not necessary for complete elimination), Mdm2 increases first, followed by an Mdm4 decrease, and finally a p53 increase. These sequential changes supported the notion that Rps27/ depletion somehow stabilizes Mdm2, which promotes Mdm4 degradation, as also shown previously (de Graaf et al., 2003; Kawai et al., 2003; Pan and Chen, 2003), leading to a suboptimal Mdm2-Mdm4 complex with reduced ligase activity toward p53, and eventually p53 accumulation.

\section{Rps27l is a ribosomal protein whose depletion triggers ribosomal stress to stabilize Mdm2}

By amino sequence comparison, Rps27l is a family member of ribosomal protein S27 (Rps27) (Xiong et al., 2011). However, it has never been determined previously whether Rps27l is indeed a ribosomal protein. By ribosomal profiling we found that like its family member Rsp27, Rps27l is localized in the ribosomes, along with other known Mdm2-binding ribosomal proteins, including Rpl5, Rpl11, and Rps7, and that Rps27l disruption does not cause obvious alterations in ribosomal profile, given the profiling patterns are largely overlapping with each other, except for the 40S peak, which is relatively lower in Rps27/-1- MEFs (Figure 5A).

We next determined whether Rps27I disruption causes aberrant ribosomal assembly. We first used qRT-PCR analysis and found that Rps27I disruption had no effect on the levels of 45S rRNA (Figure 5figure supplement 1A), indicating Rps27l loss does not impair the transcription of rDNA. Ethidium 


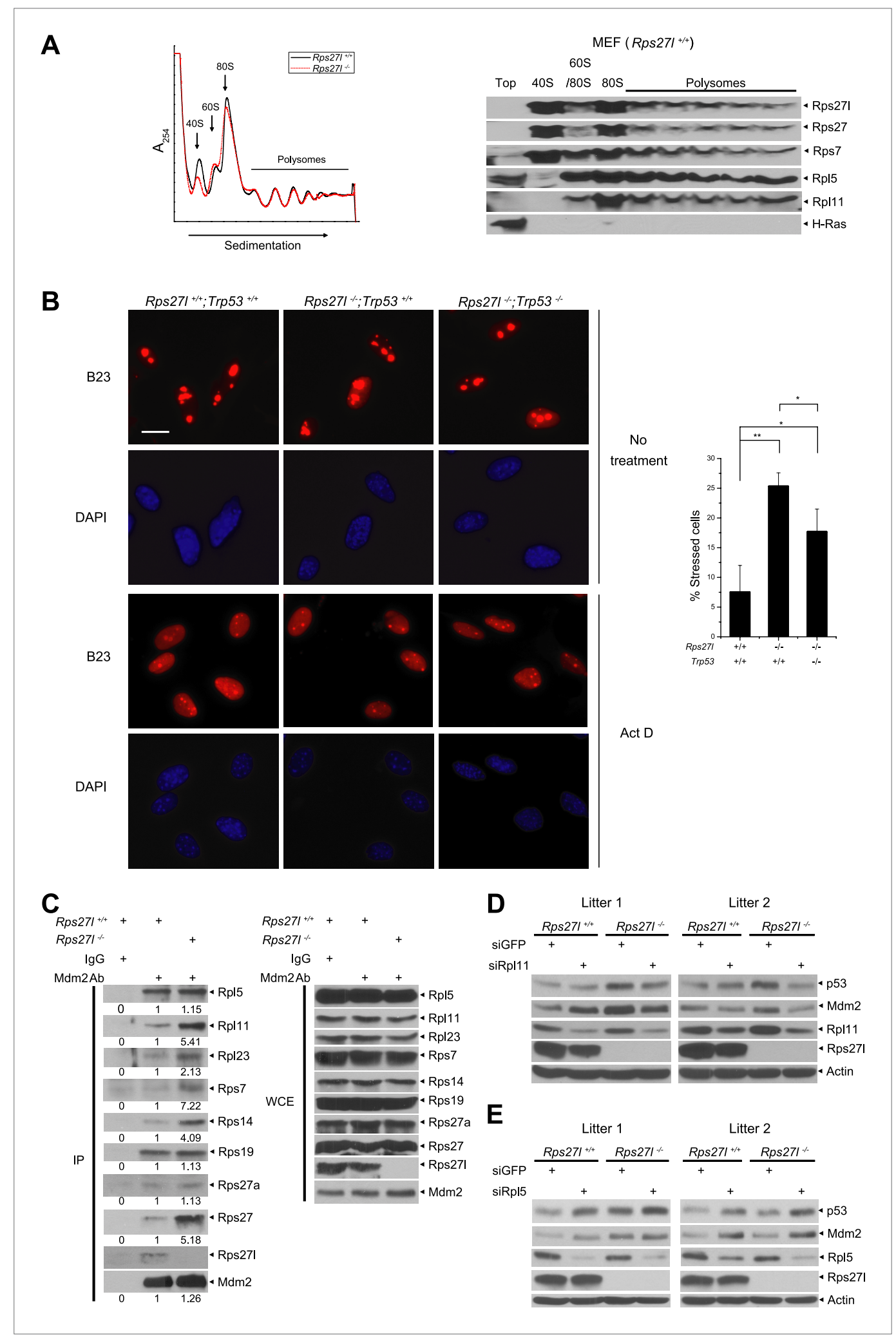

Figure 5. Rps27l is a ribosomal protein whose depletion triggers ribosomal stress. (A) Rps27l is a ribosomal protein Rps27l+/+ or Rps271/-- MEFs were treated with $\mathrm{CHX}$ for 30 min before harvesting for ribosomal profiling. The cytoplasmic extracts were loaded on sucrose gradients (10\%-50\%) and subjected to ultra-centrifugation. Gradients were then fractionated and measured by optical density at $254 \mathrm{~nm}$ (top). The fractions from Rps $277^{+/+}$MEFs were Figure 5. Continued on next page 
Figure 5. Continued

subjected to IB using indicated Abs (bottom). (B) B23 is released from nucleoli upon Rps27I depletion. MEFs with indicated genotypes were left untreated or treated with $5 \mathrm{nM}$ Act $\mathrm{D}$ for $24 \mathrm{hr}$, followed by immunofluoresent staining of B23 (left). Scale bar represents $20 \mu \mathrm{m}$. Cells with nucleolus and/or nucleoplasmic B23 staining were counted and expressed as percentage of total cells (at least 200) counted (right). Shown are mean \pm SD. ${ }^{\star *} p<0.01$;

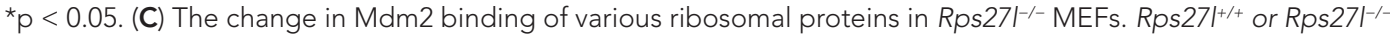
MEFs were treated with $5 \mathrm{nM}$ Act D for $4 \mathrm{hr}$ before being harvested for IP with Mdm2 Ab or normal IgG control, followed by IB with indicated Abs (left), or for direct IB with indicated Abs (right). Densitometry quantification was performed with ImageJ. ( $\mathbf{D}$ and $\mathbf{E}$ ) Activation of p53 by Rps27/-deficiency is dependent on Rpl11, but not Rpl5. Two independent pairs of MEFs were infected with lentivirus expressing short hairpin RNA (shRNA) against GFP as a negative control or against Rpl11 (D) or Rpl5 (E) before being harvested for IB with indicated Abs. DOI: 10.7554/eLife.02236.011

The following figure supplement is available for figure 5 :

Figure supplement 1. Rps27l disruption has minimal effects on rDNA transcription, rRNA processing and/or protein synthesis.

DOI: 10.7554/eLife.02236.012

bromide staining also showed a similar level of mature forms of 28S and 18S rRNAs (Figure 5-figure supplement $1 \mathrm{~B}$ ). We then performed pulse-chase labeling of rRNA and found that Rps27I loss caused a moderate decrease in the kinetics of rRNA processing from 47S to 18S (Figure 5-figure supplement $1 C, D)$. Finally, we found that Rps27l loss had no effect on global protein synthesis, as determined by a $\left[{ }^{35} \mathrm{~S}\right]$-methionine pulse-chase experiment (Figure 5-figure supplement 1E,F). Taken together, we conclude that p53 induction upon Rps27l disruption is unlikely due to aberrant protein synthesis, but reduced rRNA processing may contribute to some extent.

It is established that upon ribosomal stress a number of ribosomal proteins are released from nucleoli to bind to Mdm2, leading to its stabilization (Zhang and Lu, 2009). We then determined if Rps27I disruption triggers ribosomal stress by staining MEFs with B23/NPM, a nucleolus protein known to be released to nucleoplasm upon ribosomal stress, as a marker (Jin et al., 2004). While only $\sim 7 \%$ of

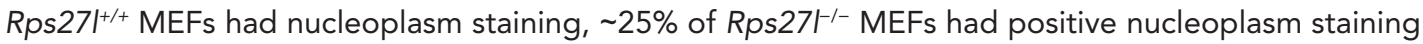
$(p<0.01)$ (Figure 5B). Positive control Act D caused nucleolar B23 release in nearly all of MEFs, regardless of Rps27l status (Figure $5 B$ ). Since p53 has been shown to constrain the ribosome biogenesis (Golomb et al., 2014), we determined potential involvement of p53 in the process and found that nucleolar B23 release was also significantly increased in $R p s 271^{-1-} ; \operatorname{Trp} 53^{-1-}$ MEFs, although to a lesser extent (7 vs 17\%) (Figure 5B). Thus, depletion of Rps27/ triggers ribosomal stress to cause B23 release from nucleoli, which is largely independent of p53.

We further determined the levels of Mdm2-bound ribosomal proteins as an independent marker for ribosomal stress (Zhang and Lu, 2009; Zhou et al., 2012). Although there is no measurable difference between Rps27/+/+ and Rps271//- MEFs (two independent pairs) in total cellular levels of several ribosomal proteins known to bind to Mdm2, including Rpl5, Rpl11, Rpl23, Rps7, Rps14, Rps19 (Figure 5figure supplement 1G), we did detect in Rps271/- MEFs an increased Mdm2 binding of Rpl11, Rpl23, Rps7, Rps14, and Rps27, but not Rpl5, Rps27a, and Rps19 (Figure 5C). Moreover, since recent studies have documented the central role of RPL5 and RPL11 in ribosomal stress-induced p53 activation (Bursac et al., 2012; Golomb et al., 2014), we determined whether activation of p53 by Rps27ldeficiency is dependent on Rpl5 and Rpl11 by siRNA-based silencing approach. In two pairs of MEFs derived from two independent littermates, silencing of Rpl11 (with enhanced Mdm2 binding upon Rps27l disruption), but not Rpl5 (without changing Mdm2 binding) abrogated the p53 activation in Rps27/-- MEFs, suggesting activation of p53 by Rps27l-deficiency is dependent on Rpl11, but not Rpl5 (Figure 5D,E). Interestingly, we reproducibly observed that Rpl5 silencing increased p53 levels in MEFs using three independent Rpl5-targeting shRNAs (Figure 5E and data not shown). Taken together, our results suggest that Rps27I disruption triggers ribosomal stress to increase the binding of Mdm2 to selective sets of ribosomal proteins, particularly Rpl11, leading to Mdm2 stabilization.

\section{Rps27I disruption destabilizes Mdm4 via Mdm2-mediated ubiquitylation and degradation}

We then addressed mechanistically how stabilized Mdm2 failed to promote p53 degradation in

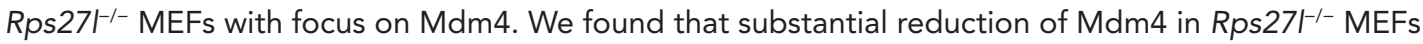


was not due to decreased Mdm4 mRNA transcription (Figure 6-figure supplement 1A), nor decreased Mdm4 mRNA translation (data not shown), but enhanced degradation, since treatment with proteasome inhibitor, MG132 for $4 \mathrm{hr}$ caused its accumulation (Figure 6-figure supplement 1B). It is noteworthy that MG132-induced accumulation of Mdm2 and p53 is much more substantial, given that both $\mathrm{Mdm} 2$ and p53 have a much shorter protein half-life.

Consistent with the fact that Mdm2 promotes Mdm4 ubiquitylation and degradation (de Graaf et al., 2003; Kawai et al., 2003; Pan and Chen, 2003) under some stressed conditions including ribosomal stress (Gilkes et al., 2006), we found Mdm4 polyubiquitylation was indeed increased with accompanied reduction of Mdm4 levels in Rps27//- MEFs (Figure 6A). Furthermore, in p53-null H1299 cells, MDM2-mediated MDM4 polyubiquitylation was substantially inhibited by ectopically expressed RPS27L (Figure 6B). A similar result was seen in 293 cells (Figure 6-figure supplement 1C). Consistently, the Mdm4 protein half-life was significantly shortened upon Rps27I disruption in MEFs (Figure 6C) or upon RPS27L knockdown in H1299 cells (Figure 6-figure supplement 1D), but significantly extended upon ectopic expression of RPS27L in H1299 cells (Figure 6-figure supplement 1E). Taken together,

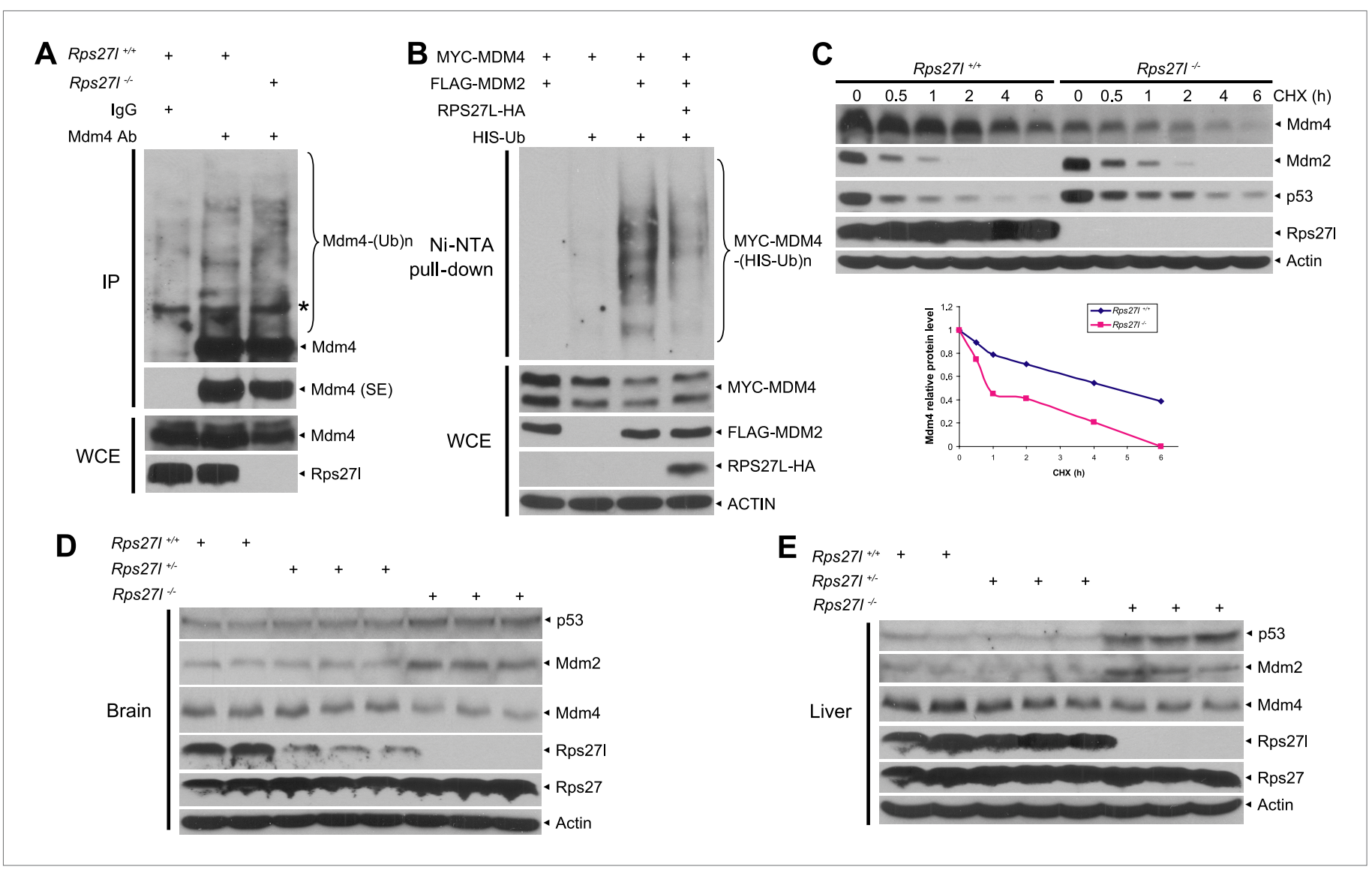

Figure 6. Rps27l depletion leads to Mdm2-mediated Mdm4 degradation. (A) Increased Mdm4 ubiquitylation upon Rps27l disruption. Rps27l+/+ or Rps27/ - MEFs were treated with MG132 before being harvested for IP with Mdm4 Ab or normal IgG control, followed by IB with Mdm4 Ab (top), or for direct IB with indicated Abs (bottom). SE: short exposure. (B) MDM2-mediated MDM4 ubiquitylation is inhibited by ectopic RPS27L. H1299 cells were transfected with indicated plasmids. At $24 \mathrm{hr}$ post-transfection, cells were treated with MG132 for $4 \mathrm{hr}$, and then harvested for purification of His-tagged ubiquitylated proteins by Ni-NTA beads, followed by IB with Myc-tag Ab to detect MDM4 ubiquitylation (top), or for direct IB with indicated Abs

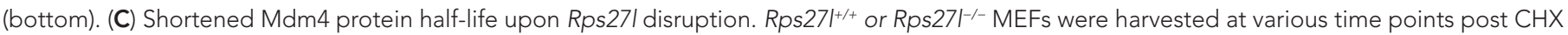
treatment for IB (top). Densitometry quantification was performed with ImageJ, and the decay curves are shown (bottom). (D and E) Increased protein levels of p53 and Mdm2 and decreased protein level of Mdm4 in Rps27//-- brains (D) and livers (E). Brain and liver tissues from P6 pups with indicated genotypes were harvested and lysed for IB.

DOI: 10.7554/eLife.02236.013

The following figure supplement is available for figure 6:

Figure supplement 1. Rps27l regulates Mdm2-mediated Mdm4 degradation.

DOI: 10.7554/eLife.02236.014 
our study demonstrated that stabilized Mdm2 upon Rps27/ depletion indeed promotes ubiquitylation and degradation of Mdm4 to reduce its cellular levels. Finally, we found a consistent increase of p53 and $\mathrm{Mdm} 2$ and a decrease of Mdm4 in several independent Rps27/-null tissues of brain and liver (Figure 6D,E).

\section{Simultaneous deletion of Trp53 rescues postnatal death and hematopoietic failure}

We next determined whether increased p53 plays a causal role in developmental defects seen in Rps $271^{-/-}$mice by simultaneous deletion of Trp53. Intercrossing of Rps271+/- $\operatorname{Trp} 53^{+/-}$mice gave rise to mice with the Rps27l/- background in combination with three p53 genotypes. All mice with Rps271--;Trp53+/+ background die within 3 weeks of age with one mouse living up to 35 days (Figure 1figure supplement 1E, Figure 7A). Consistently, HSPCs in bone marrow were significantly reduced (Figure 7-figure supplement $1 A, B$ ), as well as the peripheral blood cells (Figure 7-figure

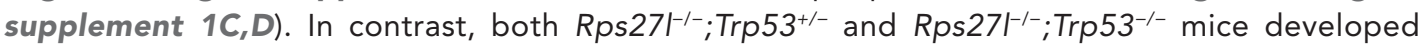
normally and are fertile with expected Mendelian distribution (Figure 7A), indicating a complete rescue of the postnatal death by either heterozygous or homozygous deletion of Trp53. Note that the life-span greater than 5 weeks was used in Figure 7A, given that the longest life-span of a Rps27/-1; Trp53 $53^{+/+}$mouse is 5 weeks (Figure 1-figure supplement 1E). At the organ and cellular levels, Trp53 deletion of either one or both alleles rescued overall defective phenotypes seen in Rps27/-- mice as follows: (1) growth retardation, as reflected by the recovery of reduced body size and weight (Figure 7B,C); (2) organ specific hypo-cellularity, as reflected by the recovery of total cell numbers in spleen, thymus and bone marrow (Figure 7D,E). On the other hand, however, the recovery of bone marrow HSPCs depletion was completely rescued by homozygous but not by heterozygous Trp53 deletion, since some of HSPCs were only partially recovered in $R p s 271^{-1-} ; \operatorname{Trp} 53^{+/-}$mice (Figure 7F,G), although it does not affect the survival of mice. Partial to complete recovery was seen in peripheral blood cells (Figure 7 H) as well as in differentiated lineages from peripheral blood (Figure 7-figure supplement 1E).

We further determined whether Trp53 deletion rescues hematopoietic failure of $R p s 27 I^{-1-}$ fetal liver. Indeed, the percentage of HSPCs was significantly increased upon deletion of one or both alleles of Trp53 (Figure $7 \mathrm{I}, J)$. More importantly, in a non-competitive reconstitution assay, inability of Rps27/ ${ }^{-1-}$ fetal liver cells to reconstitute sterilized bone marrow was rescued by heterozygous or homozygous deletion of Trp53 (Figure 7K). The percentage of donor derived cells in rescued chimeric mice approached the wild type control (Figure 7-figure supplement 1F). Thus, p53 increase upon Rps27I disruption is fully responsible for phenotypic defects observed in Rps27//- mice.

\section{Rps27I is required for genomic stability}

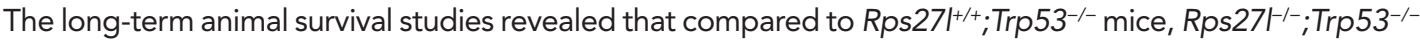
mice had a similar life-span with $\sim 50 \%$ of mice dying mainly of lymphoma at age of $\sim 150$ days (Figure 8 A, $p=0.713$, log-rank test), indicating Rps27l genotype has no effect on the life-span and lympho-

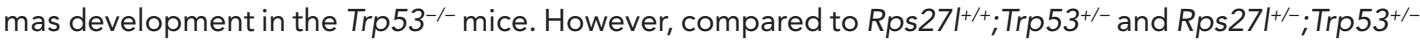
mice, Rps27//-;Trp53+- mice had a significantly shortened life-span (Figure 8B, $\mathrm{p}=0.0036$, log-rank test). Whole body necropsy revealed that out of $14 \mathrm{Rps} 2 \mathrm{II}^{-1-} ; \operatorname{Trp} 53^{+--}$mice died within a period of 400 days ( $50 \%$ death rate), seven developed T-lymphoblastic lymphoma (Figure $8 C, D)$, one developed T-cell lymphoma detected in tissues of thymus, lymph node and spleen (Figure 8-figure supplement 1A), and one developed B-cell lymphoma seen in a much enlarged lymph node (Figure 8figure supplement 1B). The remaining mice had enlarged liver and/or spleen (not shown). The results indicate that Rps27l disruption accelerated the formation of spontaneous lymphomas under the Trp53 ${ }^{+/-}$background. We then collected more lymphoma tissues from $R p s 271^{-1-} ; \operatorname{Trp} 53^{+/-}$mice at age of 4-6 months for Trp53 genotyping and found that the wild type Trp53 allele was deleted in 29 out of 30 (97\%) lymphomas genotyped (Figure 8-figure supplement 1C,D), indicating that Rps27l disruption imposed the selection pressure against wild-type Trp53. We further measured the genome integrity of these lymphoma cells by metaphase chromosome spread and found a high degree of aneuploidy in up to $63 \%$ of total population (Figure $8 \mathrm{E}$, Figure 8 -figure supplement 1E). Centromerecentromere fusions were also seen in some diploid lymphoma cells (Figure 8E, arrow). Thus, Rps27l disruption causes genomic instability and Trp53 deletion, eventually leading to lymphoma development. To determine which event (genomic instability vs Trp53 deletion) occurs first, we performed 
A Deletion of Trp53 allele rescues postnatal death induced by Rps27/ disruption

\begin{tabular}{|c|c|c|c|c|c|c|c|c|c|c|}
\hline & \multicolumn{3}{|c|}{ Rps271+// } & \multicolumn{3}{c|}{ Rps271 +/ } & \multicolumn{3}{c|}{ Rps271/ } & Total \\
\hline Trp53 & $+/+$ & $+/-$ & $-/$ & $+/+$ & $+/-$ & -- & $+/+$ & $+/$ & $-/$ & \\
\hline No. of mice (>5wks) & 47 & 72 & 23 & 109 & 174 & 48 & 0 & 60 & 22 & 553 \\
\hline Expected ratio & $1 / 16$ & $1 / 8$ & $1 / 16$ & $1 / 8$ & $1 / 4$ & $1 / 8$ & $1 / 16$ & $1 / 8$ & $1 / 16$ & \\
\hline
\end{tabular}

B

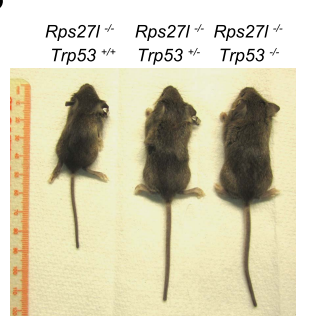

E

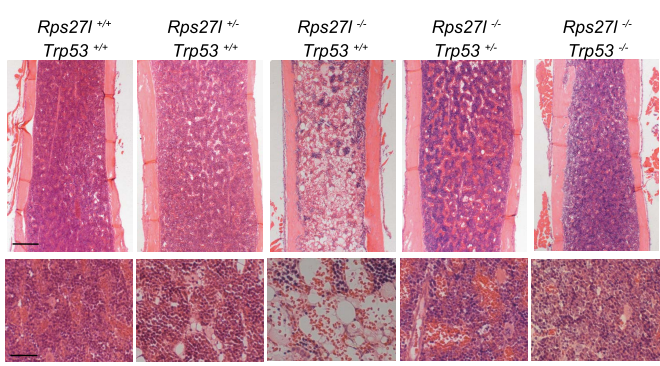

G

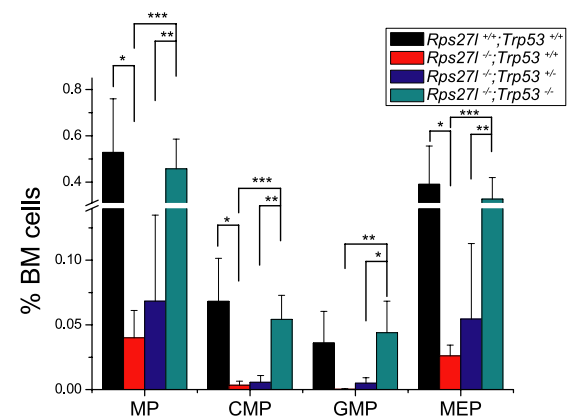

C

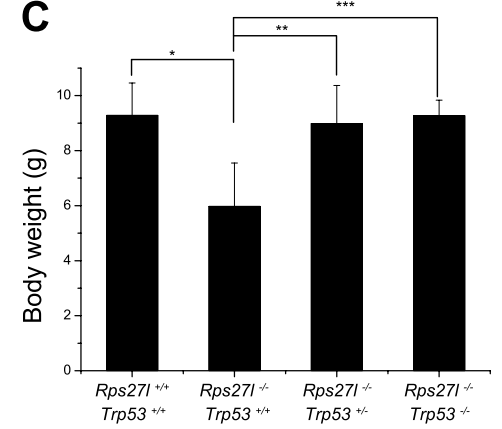

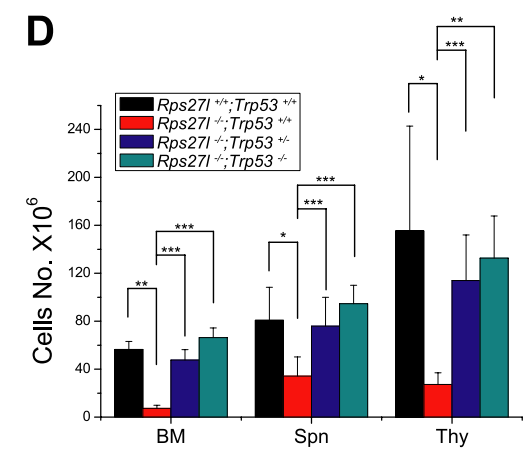

$F$

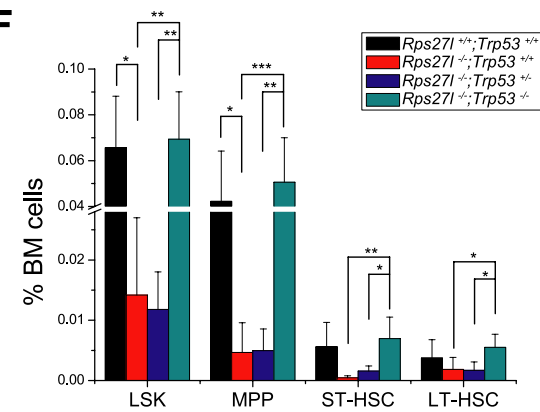

H
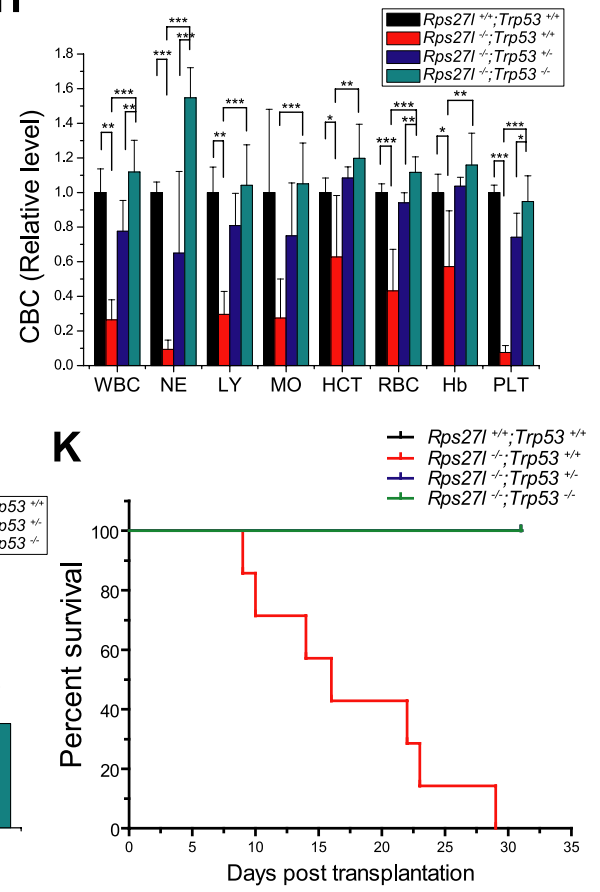

Figure 7. Simultaneous deletion of Trp53 rescues growth retardation and HSPCs depletion. (A) Deletion of Trp53 rescues postnatal death by Rps27l disruption. Lower than expected number of mice with Trp53/-- genotype (regardless of Rps27I genotype) is due to high frequency of developmental abnormalities during embryonic and neonatal stages which cause the premature death (Armstrong et alı, 1995; Sah et al., 1995). (B-D) Deletion of Trp53 rescues growth retardation and organ hypocellularity. Representative mice at P18 of three genotypes were photographed (B). The bodies (C) were Figure 7. Continued on next page 
Figure 7. Continued

weighed; and the total cell numbers (D) of bone marrow (femur and tibia from two hind limbs), spleen, and thymus were counted from P18 mice with

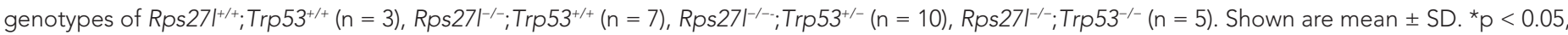
${ }^{* *} p<0.01$, and ${ }^{* \star *} p<0.001$. (E) Representative H\&E staining of bone marrows in femurs from P18 mice. Scale bars represent $200 \mu \mathrm{m}$ (top) or $40 \mu \mathrm{m}$ (bottom). (F and G) Deletion of Trp53 rescues HSPCs depletion in Rps271/-- bone marrow. The percentage of LSK, MPP, ST-HSC, and LT-HSC (F); and the

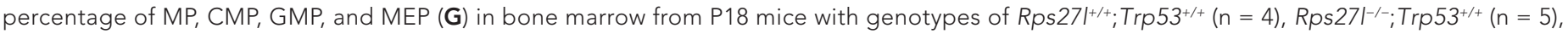

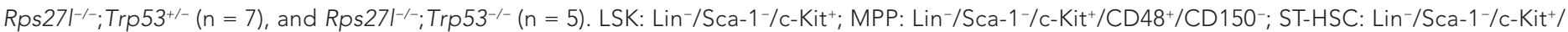
CD48+CD150+; LT-HSC: Lin-/Sca-1-/c-Kit+CD48-/CD150+. Shown are mean \pm SD. ${ }^{*} p<0.05,{ }^{* *} p<0.01$, and ${ }^{* * *} p<0.001$. (H) Deletion of Trp53 rescues

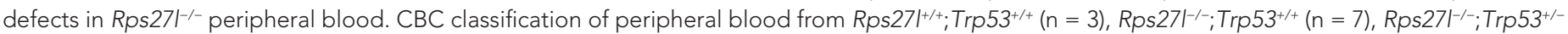
$(n=10)$, Rps27/-- ;Trp53--- $(n=5)$ mice at P18 was performed. WBC, white blood cells; NE, neutrophils; LY, lymphocytes; MO, monocytes; HCT, hematocrit; RBC, red blood cells; Hb, hemoglobin; PLT, platelets. Shown are mean \pm SD. ${ }^{\star} p<0.05$, ${ }^{* *} p<0.01$, and ${ }^{* * *} p<0.001$. (I and $\left.\mathbf{J}\right)$ Deletion of Trp53 rescues HSPCs depletion in Rps27/ $1-$ fetal livers. Flow cytometry analysis was performed to measure the percentage of HSPCs including LSK (I), MP,

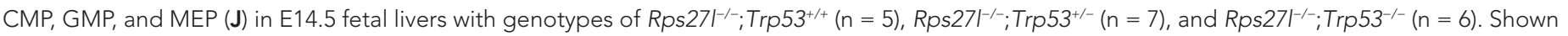

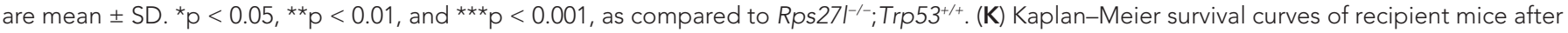
transplantation. Fetal liver cells $\left(2 \times 10^{6}\right.$ cells $)$ from E14.5 embryos with indicated genotypes were respectively injected into lethally irradiated recipient mice ( $n=7$ for each genotype). $p<0.0001$

DOI: 10.7554/eLife.02236.015

The following figure supplement is available for figure 7 :

Figure supplement 1. Simultaneous deletion of Trp53 rescues defective phenotypes caused by Rps27l disruption. DOI: 10.7554/eLife.02236.016

the same metaphase chromosome spread in four independent pairs of early passage primary MEFs and found a significant higher rate of chromosomal aneuploidy in Rps27/ ${ }^{-1-} ; \operatorname{Trp} 53^{+/-}$cells than in Rps $271^{+/+} ; \operatorname{Trp} 53^{+/-}$cells (30\% vs 15\%) (Figure 8F), although wild-type Trp53 was retained, as measured by qPCR (Figure $8 \mathrm{G}$ ). Thus, Rps27l disruption triggers genomic instability prior to Trp53 deletion and the cells with subsequent Trp53 deletion are selected, which outgrow to form spontaneous lymphoma. We further performed the same metaphase chromosome spread in MEFs with the genotype of

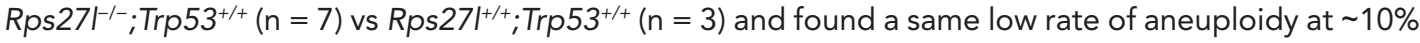
in both group of MEFs (Figure $8 \mathrm{H}$ ). Thus, Rps27/ disruption triggers genomic instability only when one allele of Trp53 is deleted or mutated.

Our results implied that Rps27I depletion is responsible for genomic instability by a mechanism that appears to be independent of p53 loss. To further test this, we measured the levels of p53 and its upstream and downstream regulators in three independent pairs of MEFs of Rps $27 I^{-1-}$; Trp $53^{+/-}$vs the littermates of Rps271/++; Trp53 ${ }^{+/-}$, and found that in every case, both basal and induced (by ActD) levels of p53 and p53 downstream (p21 and Mdm2) are higher in Rps27I-null MEFs than in Rps27l-wt MEFs, whereas the p19/Arf level was lower in the former (Figure 8I,J). These results demonstrated that Rps27I disruption induces genomic instability under Trp53+/- background, which triggers p53 to balance the genome, and is indeed independent of p53 loss. On the other hand, Rps27l disruption also confers a selective pressure against p19/Arf, a p53 upstream regulator, although the underlying mechanism is unclear. Nevertheless, p19/Arf reduction would likely contribute to observed Mdm2 increase to degrade Mdm4, leading to p53 accumulation. Finally, it is worth noting that p53 level and activity

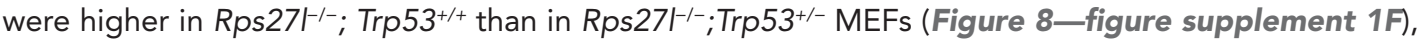
and this difference, likely extendable to other organs, such as bone marrow, determines the life and death of mice at the postnatal stages.

\section{Discussion}

\section{Rps27l is an essential gene for postnatal development by modulating p53}

In this study, we demonstrated, using a gene-trap mouse model that Rps27l, a p53 downstream ribosomal protein and an Mdm2 E3 ligase substrate, is essential for mouse development. Rps27I disruption causes a moderate increase of p53 which is sufficient to deplete HSPCs in fetal livers and bone marrows, eventually to cause the postnatal death. By both noncompetitive and competitive reconstruction assays, we clearly demonstrated that the HSPCs from Rps27/l- fetal livers were unable to reconstitute sterilized bone marrow. Rescuing of these defects by simultaneous deletion of a single or both alleles of Trp53 indicates that p53 plays a causal role and that a moderate p53 increase is responsible for and sufficient to cause the depletion of these HSPCs via inducing apoptosis. It is noting worthy that although, unlike homozygous Trp53 deletion, heterozygous Trp53 deletion 


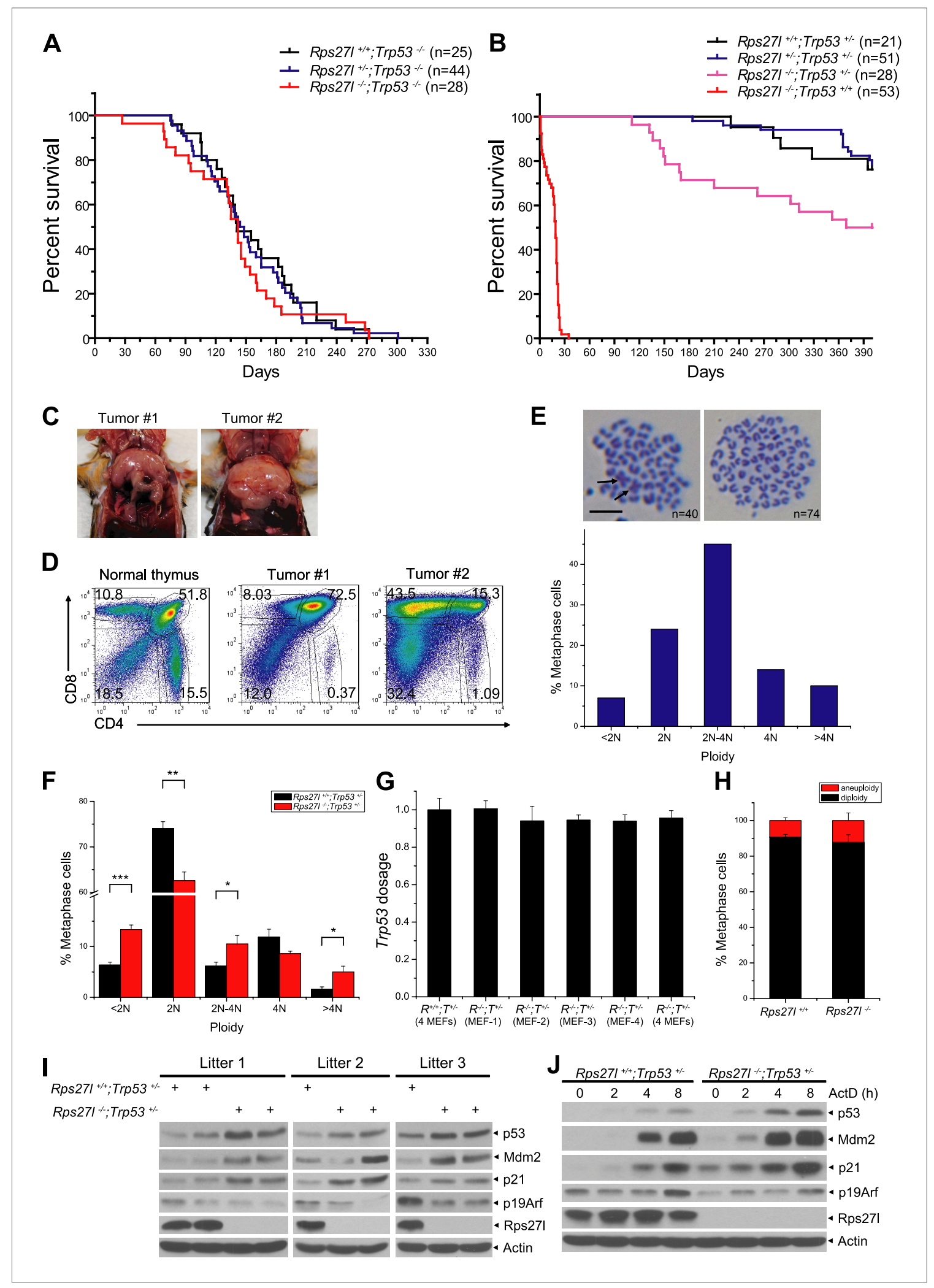

Figure 8. Rps27l disruption induces genomic instability and spontaneous lymphoma. (A and B) Kaplan-Meier survival curves of Trp53-/- (A) and Trp53+/- (B) mice with three Rps27l genotypes and indicated numbers of mice. $p=0.713$ (A); $p=0.0036$ (B). (C) Representative pictures of lymphomas developed from Rps271/-; Trp53+/- mice. (D) Representative FACS profiles of T cells from lymphomas. Lymphoma cells were isolated and subjected to Figure 8. Continued on next page 
Figure 8. Continued

FACS analysis using Abs against indicated surface markers. (E) Representative pictures of metaphases from four tumors developed from Rps27/-1-; Trp53 $3^{+/}$mice (top). Chromosome numbers (n) were counted. Scale bar represent $10 \mu \mathrm{m}$. Frequency of diploid and aneuploidy from four tumors

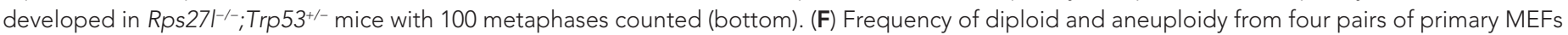

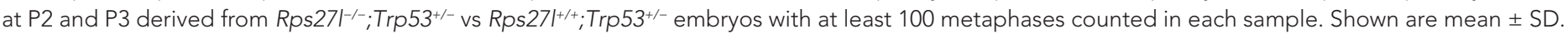
${ }^{\star} \mathrm{p}<0.05,{ }^{* \star} \mathrm{p}<0.01$, and ${ }^{* \star *} \mathrm{p}<0.001$. (G) Trp53 dosage in four pairs of primary MEFs at P3 derived from Rps $271^{-1-} ; \operatorname{Trp} 53^{+/-}\left(R^{-1-} ; T^{+/-}\right)$vs $\operatorname{Rps} 27 \mathrm{I}^{+/+} ; \operatorname{Trp} 53^{+/-}$ $\left(R^{+++} ; T^{+/-}\right)$embryos. Amounts of p53 DNA in individual MEFs were quantified by qPCR using three sets of primers for exons 5, 6, and 7. The combined results $\left(\mathrm{n}=3\right.$ for each primer set, mean \pm SD) were presented with the values from Rps $27 \mathrm{I}^{+/+} ;$Trp $53^{+/-}$MEFs averaged and set as 1 . (H) Frequency of diploid

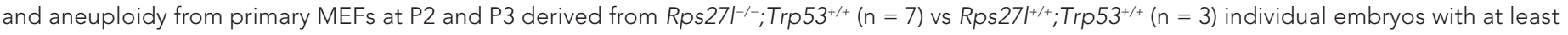
100 metaphases counted in each sample. Shown are mean \pm SD. $p=0.15$. (I and $\mathbf{J}$ ) Increased levels of p53 and p53 targets and decreased levels of Arf

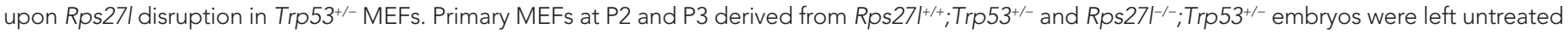
(I) or treated with $5 \mathrm{nM} \mathrm{ActD}$ for indicated time periods (J) before being harvested for IB with indicated Abs.

DOI: 10.7554/eLife.02236.017

The following figure supplement is available for figure 8:

Figure supplement 1. Rps27l disruption induces genomic instability and spontaneous lymphoma. DOI: 10.7554/eLife.02236.018

fails to completely rescue the defects in number or percentage of HSPCs in the bone marrows in p18 weaning mice, it is still sufficient to rescue the postnatal growth retardation and death.

\section{Rps27l is a ribosomal protein that triggers ribosomal stress upon depletion to induce p53}

An increasing list of ribosomal proteins (RPs) has been shown in numerous in vitro cell culture studies to bind to Mdm2 and stabilize p53, thus acting as a p53 activator (Zhang and Lu, 2009; Zhou et al., 2012). It was also reported that siRNA silencing of some ribosomal proteins, such as $L 23$, triggered ribosomal stress, leading to p53 stabilization and activation (Dai et al., 2004; Jin et alo, 2004). We previously showed that RPS27L is an MDM2 binding protein whose overexpression inhibits MDM2mediated p53 ubiquitylation, whereas its silencing reduces p53 in some cancer lines (e.g., A549 and SJSA), but not in others (e.g., SY5Y, MCF7, U2OS, HCT116, and RKO) (Xiong et al., 2011) (data not shown), suggesting RPS27L might act as a p53 activator in a cancer cell dependent manner. Here we reported that Rps27l is indeed a ribosomal protein, whose depletion triggers ribosomal stress (as evidenced by B23 nucleoplasm staining and enhanced RPs-Mdm2 binding) with moderate reduction in ribosomal RNA processing, but no effect on general protein synthesis. We further found, using Rps27I $\mathrm{KO}$ model, that unlike in vitro cell culture studies which showed that almost all known MDM2-binding ribosomal proteins acts as p53 activators upon overexpression (Zhang and Lu, 2009; Zhou et al., 2012), Rps27l actually activates p53 upon disruption, given the fact that (a) Rps27l deletion caused p53 accumulation in multiple organs as well as in primary MEFs, and (b) all Rps27l-null phenotypes, such as depletion of HPSCs and bone marrow, growth retardation and postnatal death, can be fully rescued by Trp53 deletion. It is conceivable that the discrepancy between in vitro and in vivo studies is likely attributable to the fact that most cell culture studies were conducted (a) in human cancer cell lines with multiple genetic alterations, (b) under artificial overexpression and/or (c) partial RNA silencing conditions. Nevertheless, through this knockout study we conclusively showed that Rps27/ disruption induces p53 under the physiological conditions in a manner independent of DNA damage. It is also interesting in our finding that consistent with enhanced binding of Mdm2-Rpl11, but not Mdm2Rpl5, p53 induction triggered by Rps27/ disruption is dependent of Rpl11, but independent of Rpl5, although both are key ribosomal proteins, released from nucleolus upon ribosomal stress, to inhibit Mdm2-mediated p53 degradation (Golomb et al., 2014). Furthermore, we made a novel observation that Rps27/ disruption caused an increased binding of Mdm2 selectively to Rpl11, Rpl23, Rps7, Rps14, and Rps27, but not to Rpl5, Rps27a, and Rps19. Whether these RPs with enhanced Mdm2 binding indeed contribute to p53 activation in Rps27/-deficient MEFs is an interesting topic warranting future investigation.

\section{Rps27l regulates the Mdm2-Mdm4 E3 ligase activity towards p53}

Our Rps27l acute depletion experiment conducted in both Trp53-wt and Trp53-null MEFs clearly showed a sequential change in the levels of Mdm2 (increase), Mdm4 (decrease) and p53 (increase), indicating that (1) Rps27/ depletion induces p53-independent Mdm2 increase and (2) increased Mdm2 fails to degrade p53. Our follow-up experiments mechanistically addressed these two fundamental 
questions: how Mdm2 is increased upon Rps27/ disruption and why increased Mdm2 fails to degrade p53 in the absence of Rps27l. For first question, we found that while Rps27l has no direct effect on Mdm2 mRNA transcription, it indeed negatively regulates the Mdm2 protein stability with Mdm2 protein half-life being extended or shortened upon Rps27I depletion or overexpression, respectively. It is conceivable that in wt cells under unstressed conditions, Rps27l binds to Mdm2 on its acidic domain (Xiong et al., 2011), which has potential to block the binding of other ribosomal proteins (e.g., L11/ $\mathrm{S} 7 / \mathrm{S} 27 \mathrm{a} / \mathrm{S} 14$ ) to $\mathrm{Mdm} 2$ on the same domain (internal competition). Upon Rps27l disruption, which triggers ribosomal stress, other ribosomal proteins are released from nucleoli and bind to $\mathrm{Mdm} 2$ on an unoccupied acidic domain to inhibit Mdm2 self-ubiquitylation, leading to its stabilization. To address the second question, we showed that the total Mdm4 level was significantly lower in Rps27/ ${ }^{-1-}$ than in Rps27/+++ MEFs. We also showed by both loss-of-function and rescue-of-function studies that Mdm2mediated Mdm4 ubiquitylation and degradation is negatively regulated by Rps27l, being enhanced upon Rps27l depletion and reduced upon RPS27L overexpression. Thus, enhanced Mdm2-RPs binding (such as Mdm2-Rpl11 binding) as a result of ribosomal stress in response to Rps27l disruption would facilitate Mdm2-dependent Mdm4 degradation, which is consistent with a previous observation (Gilkes et al., 2006). Furthermore, we found that although Mdm2-Mdm4 has a better affinity upon Rps27I deletion, a much reduced amount of Mdm4 in Rps27/-- MEFs results in a reduced level of Mdm2bound Mdm4, thus lesser formation of the Mdm2-Mdm4 heterodimer. Given that Mdm2-Mdm4 heterodimer is the most stable and active form of E3 ligase for targeted p53 degradation, as shown in both in vitro (Kawai et al., 2007; Wang et al., 2011) and in vivo (Francoz et al., 2006; Garcia et al., 2011; Huang et al., 2011; Pant et al., 2011) studies, compromised Mdm2-Mdm4 ligase activity in Rps27/ $1^{--}$MEFs leads to a reduced p53 ubiquitylation and degradation, consequently an extended p53 protein half-life and increased p53 levels.

\section{Lessons from the Rps27I mutant mice}

While numerous gene knockout studies have shown an involvement of p53 during embryogenesis, the causal role played by p53 was best demonstrated by the total knockout of Mdm2 (Jones et al., 1995; Montes de Oca Luna et al., 1995) or Mdm4 (Parant et al., 2001; Finch et al., 2002; Migliorini et al., 2002) and by the knock-in (KI) of mutant Mdm2 $2^{\mathrm{C462A}}$ (Itahana et al., 2007), Mdm4 $4^{\mathrm{C} 462 \mathrm{~A}}$ (Huang et al., 2011), or Mdm4 $4^{\Delta R I N G}$ (Pant et al., 2011). In all cases, p53 is accumulated to robust levels to kill the embryos at the early stage of embryogenesis, which can only be rescued by homozygous, but not heterozygous, deletion of Trp53 (Jones et al., 1995; Montes de Oca Luna et al., 1995; Parant et al., 2001; Itahana et al., 2007; Huang et al., 2011; Pant et al., 2011). In addition, the embryonic lethality of $\mathrm{Mdm} 2^{-/-}$mice can also be rescued by Trp53515C, a hypomorphic allele of $\mathrm{p} 53$, which encodes

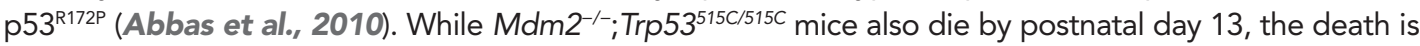
mainly attributable to depletion of HPSCs in postnatal bone marrows, but not in fetal liver due to p53 $3^{\text {R172P }}$-induced ROS generation, and subsequent senescence and cell death (Abbas et al., 2010). In contrast, Rps27l disruption causes a moderate increase of p53 which is insufficient to induce embryonic lethality, but sufficient to induce postnatal lethality, resulting from apoptotic depletion of HPSCs in both fetal liver and neonatal bone marrow. The Trp53 dosage effect has also been seen in Mdm2+/and $\mathrm{Mdm}^{+/-}$double heterozygous embryos and mice (Terzian et al., 2007).

Besides its engagement in the $\mathrm{Mdm} 2 / \mathrm{Mdm} 4 \mathrm{KO} / \mathrm{Kl}$ studies, p53 was found to be activated upon impairment of ribosome biogenesis in several RP-deficient mouse models (Bursac et alo, 2014). For example, liver specific deletion of Rps6 prevented hepatocytes from re-entering the cell cycle after partial hepatectomy due to increased p53, which can be rescued by Trp53 deletion (Volarevic et al., 2000; Fumagalli et al., 2009). Developmental defects derived from tissue specific deletion of Rps6 in T cells or oocytes was largely due to p53 activation, and rescued by Trp53 deletion (Sulic et al., 2005; Panic et al., 2006). Likewise, p53 activation was involved in defective $\alpha \beta$ T cell development in Rpl22 knockout mice and this deficiency was completely rescued by Trp53 deletion (Anderson et al., 2007). p53 activation was also involved in congenital malformations in Rp/24-deficient mice which were largely rescued by p53 ablation (Barkic et al., 2009). Furthermore, phenotypes such as cerebellar ataxia, pancytopenia and epidermal hyperpigmentation seen in Rp/27a mutant mice was rescued in a haploinsufficient Trp53 background (Terzian et al., 2011), whereas the dark skin as a result of p53-dependent epidermal melanocytosis seen in Rps6, Rps19, or Rps20 mutant mice was also rescued by Trp53 deletion (McGowan et al., 2008). Finally, p53 appears to be causally related to the defects seen in the Treacher Collins syndrome (TCS), a congenital disorder of craniofacial development arising 
from mutations of TCOF1, which encodes the nucleolar phosphoprotein Treacle and whose haploinsufficiency perturbs mature ribosome biogenesis to trigger p53 activation (Jones et al., 2008).

Only one mouse $\mathrm{KO}$ model involving the deletion of an Mdm2-binding ribosomal protein Rps14, along with other seven known genes (deletion of Cd74-Nid67 interval) in the 5q-syndrome, was previously reported (Barlow et alo, 2010). Hematological abnormalities associated with increased apoptosis in bone marrow progenitor cells can be rescued only by homozygous Trp53 deletion (Barlow et al., 2010). To our best knowledge, our study is the first targeted inactivation of a single Mdm2-binding ribosomal protein in mouse and demonstrated that (1) Rps27l is required in vivo to keep p53 in check and (2) developmental defects and postnatal death upon Rps27/ disruption are rescued by the deletion of single Trp53 allele, indicating that moderate increase of p53 is sufficient to tip the life-death balance to the death. It is worth noting that postnatal death upon Rps27l disruption occurs under the wt background of its family member, Rps27 as well as other ribosomal genes encoding all known Mdm2-binding ribosomal proteins. Thus, for hematopoiesis, Rps27l plays a non-redundant role in reducing p53 levels via stabilizing the Mdm2-Mdm4 complex.

\section{Rps27l regulates genomic stability}

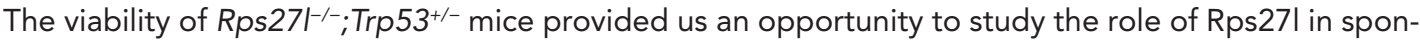
taneous tumorigenesis. Surprisingly, while moderate p53 increase is expected to decrease the tumor incidence as shown in Mdm2 hypomorphic mice (Mendrysa et al., 2006) and in $\mathrm{Mdm}^{+/-}$or $\mathrm{Mdm}^{+/-}$

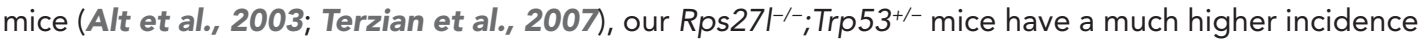

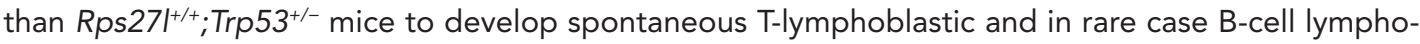
mas, resulting in a shortened life-span. In 97\% of tumor tissues genotyped, wt Trp53 allele was deleted, indicating that Rps27l depletion imposes a selection pressure against p53. Furthermore, the genome of these lymphoma cells is highly unstable with a strike aneuploidy rate of $\sim 63 \%$, which is remarkably higher than those derived from Trp53-null mice with an aneuploidy rate of 30-35\% (Kibe et al., 2012). Even in diploid population, abnormal centromere-centromere fusions were found. Thus, our study provides an in vivo demonstration that Rps27l is required for the maintenance of genomic stability, which is consistent with a previous report, showing that RPS27L knockdown in HCT116 colon cancer cells may trigger genomic instability (Li et al., 2007).

One more striking observation we made in this study is that the genomic instability occurs in early

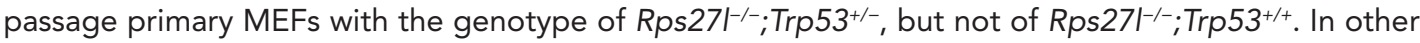
word, Rps27l plays a limited role in the maintenance of genomic stability, if p53 is normal. However, when one allele of Trp53 is deleted or mutated (such as in the case of Li-Fraumeni syndrome or at various stage of tumorigenesis), Rps27l becomes critically essential in preventing the loss of p53 heterozygosity. Thus, its loss or decreased expression by any means would exacerbate genomic instability and provide selection pressure against p53, eventually leading to tumor development. Potential tumor suppressive function of RPS27L is further supported by an observation that high level of RPS27L expression predicted a better prognosis in colon cancer patients (Huang et al., 2013).

In summary, our results provide strong pieces of in vivo evidence that Rps27I precisely regulates p53 threshold. In normal cells with wt p53 (Trp53 ${ }^{+/+}$status), Rps27l appears to be a physiological inhibitor of p53 through optimizing Mdm2-Mdm4 E3 ligase activity towards p53 to keep p53 in check. Rps27/ disruption triggers ribosomal stress to increase $\mathrm{Mdm} 2$ for targeted Mdm4 degradation, leading to p53 activation (in an Rpl11 dependent manner) and subsequent apoptosis induction and postnatal death. Under Trp53 $3^{+-}$status, Rps 27 acts as a tumor suppressor by maintaining the genomic stability and preventing Trp53 deletion. Rps27/ disruption triggers genomic instability and confers selection pressure for p53 inactivation, leading to lymphamagenesis (Figure 9). Whether the RPS27L level determines the early-onset of human cancers in Li-Fraumeni syndrome patients with a germ-line TP53 ${ }^{+/}$status is certainly an intriguing question that deserves further investigation.

\section{Materials and methods}

\section{Generation of Rps27l gene trapped mice}

Germline-transmitted heterozygous Rps27/ mice generated from an ES cell clone (IST11658B7, C57BL/6) were obtained from the Texas A\&M Institute for Genomic Medicine (TIGM, College Station, TX). Germline transmission was confirmed by PCR and Southern blotting. Mice bearing the Trp53-null allele (deletion of exons 2-7) (Jacks et al., 1994) were provided by Dr Yuan Zhu (University of Michigan, 


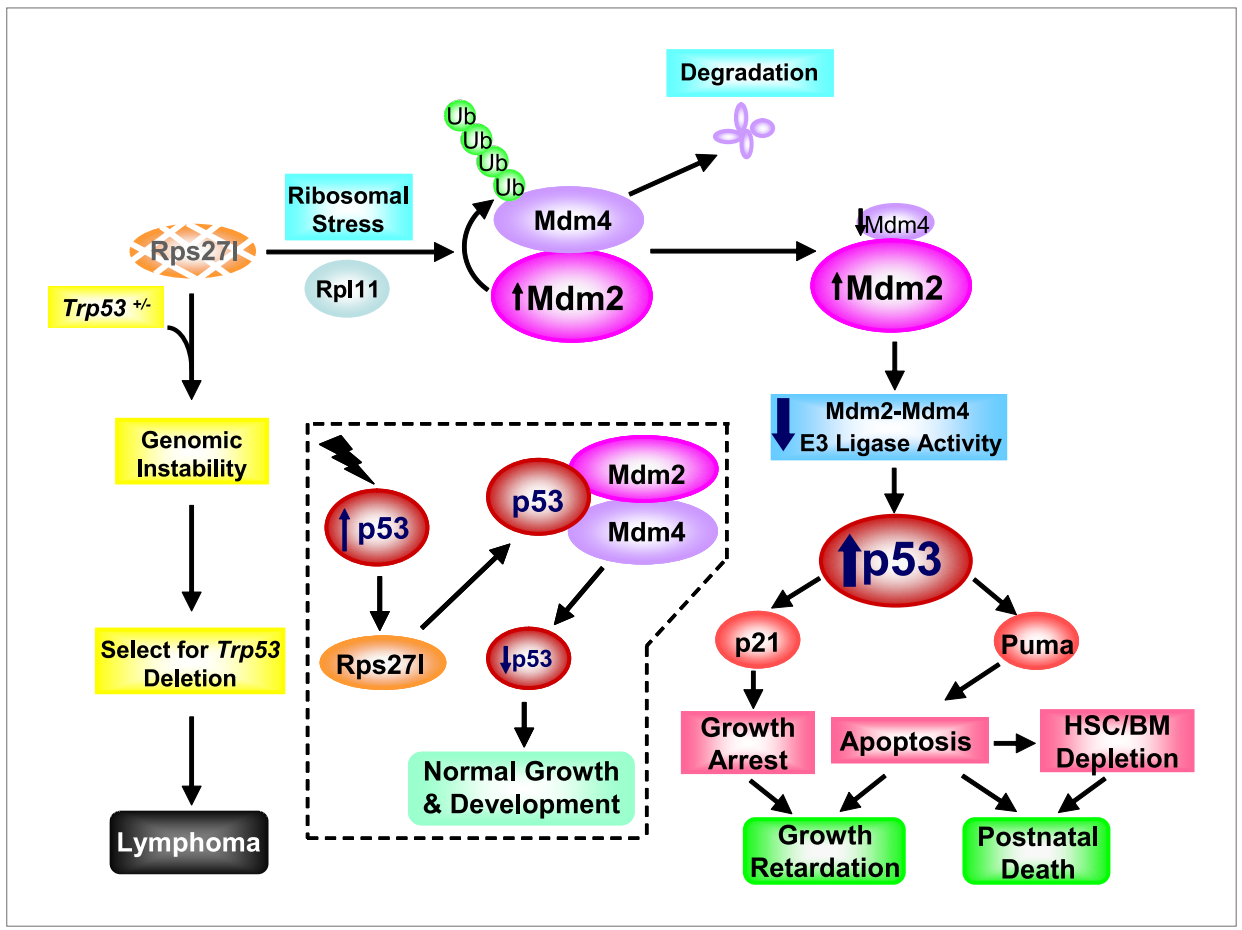

Figure 9. Rps27l is a p53 regulator and also a p53 'goalkeeper' - a working model. In normal cell with wild-type p53 $\left(\operatorname{Trp} 53^{+/+}\right)$, Rps27l, upon induction by p53 in response to various stresses, stabilizes the Mdm2-Mdm4 heterodimer to form an optimal E3 ligase complex for effective p53 ubiquitylation and degradation, thus keeping p53 level in check, leading to normal growth and development (dotted area). Rps27l disruption causes an imbalance in ribosomal protein levels and triggers ribosomal stress to stabilize Mdm2. Increased Mdm2 adapts a conformation that favors the Mdm4 ubiquitylation, leading to a reduced Mdm2-Mdm4 complex and compromised p53 ubiquitylation with an ultimate increase in p53. Moderately increased p53 is sufficient to induce growth retardation and apoptosis by transactivating p21 and Puma, respectively, leading to the depletion of HSPCs and bone marrow, and eventually postnatal death. In cancer-prone cells with a Trp53 $3^{+-}$status, Rps27I plays an essential role in keeping genome integrity. Rps27l disruption triggers genomic instability, followed by selection for Trp53 deletion. The cells with Trp53 deleted are selected for and outgrow to form spontaneous lymphoma.

DOI: 10.7554/eLife.02236.019

Ann Arbor, MI). The genetic background of Rps27I mutant mice is pure C57/BL6, while Rps27l/ Trp53 mice are the hybrids of $129 \mathrm{Svj}$ and C57BL/6. C57BL/6 Ly5.2 (CD45.1) mice were purchased from the National Cancer Institute. All procedures were approved by the University of Michigan Committee on Use and Care of Animals. Animal care was provided in accordance with the principles and procedures outlined in the National Research Council Guide for the Care and Use of Laboratory Animals.

\section{PCR-based genotyping}

Genomic DNA was isolated from mouse tail tips according to University of Michigan Transgenic Animal Model Core protocol (http://www.med.umich.edu/tamc/tDNA.html). Mice were genotyped using the primer set of LTR-Rev 2: 5'-ACC TGA AAT GAC CCT GTG CCT TA-3' and IST11658B7-f: 5'-TTG ATG GCT ACC CAG CCA AAC G-3' for Rps27l mutant (325 bp) and IST11658B7-f and IST11658B7-r2: 5'ACG TAT CCT TTA CCT GGC TCC C-3' for Rps27/ wt (525 bp). The primer sets for Trp53 genotyping are p53×6.5: 5'-ACA GCG TGG TGG TAC CTT AT-3'; p53x7: 5'-TAT ACT CAG AGC CGG CCT-3'; and p53 Neo19: 5'-CAT TCA GGA CAT AGC GTT-3'.

\section{Southern analysis}

Genomic DNA was isolated from mouse tails and digested with EcoRI or Pstl. The $5^{\prime}$ end probe (644 bp) was generated by PCR using the primer set, S27LKO-5pb-F: 5'-TAA GCC AGG GGG TCA ATA-3' and S27LKO-5pb-R: 5'-CTC CCC TGT TCA TTG TGC-3'. The $\beta$-Gal probe (686 bp) was generated by PCR using the primer set, S27LKO-BG-F: 5'-GGC GTA ATA GCG AAG AGG-3', and S27LKO-BG-R: 
5'-TTC ACC CTG CCA TAA AGA-3'. All the probes were confirmed by DNA sequencing. Southern blot analysis was carried out as described (Tan et al., 2009).

\section{Generation and maintenance of MEFs}

MEF cells were generated from day E13.5 embryos with indicated genotypes as described (Tan et al., 2009), and cultured in DMEM with 15\% FBS, 2 mM L-Glutamine, $0.1 \mathrm{mM}$ MEM non-essential amino acids at $37^{\circ} \mathrm{C}$ in a $5 \% \mathrm{CO} 2$ humidified chamber.

\section{Immunofluorescence}

Paraffin sections were deparaffinized, rehydrated, and analyzed by immunofluorescence (Wang et alı, 2009a). The tissue sections were incubated with antibody against cleaved caspase-3 (Cell signaling Technology, Danvers, MA) in blocking solution overnight. MEF cells were left untreated or treated for $24 \mathrm{hr}$ with ribosomal stress inducer, actinomycin $\mathrm{D}(5 \mathrm{nM})$, followed by immune-staining with antibody against B23 (Sigma, St. Louis, MO). The secondary antibodies were conjugates of Alexa Fluor 488 or Alexa Fluor 594 (Life Technologies, Grand Island, NY). DAPI (Life Technologies) was used as nuclear counterstaining. Stained tissues or cells were examined under a fluorescence microscope (Olympus, Center Valley, PA).

\section{Western blotting and immunoprecipitation}

Cells or tissues were harvested, lysed and subjected to Western blotting or immunoprecipitation (Macias et al., 2010), using various antibodies as follows: RPS27L or RPS27 polyclonal rabbit antibody was raised and purified as described (He and Sun, 2007), p53 (1C12 from Cell signaling technology and CM5p from Leica Microsystems, Buffalo Grove, IL), Mdm2 4B2 and Mdm4 7A8 (gifts from Dr Jiandong Chen), rabbit polyclonal Mdm4 (gift from Dr Aart Jochemsen, used for IP), Rpl5, Rpl11, and Rpl23 (gifts from Drs Yanping Zhang and Hua Lu), Rps7 (gift from Dr Ruiwen Zhang), Rps27a (gift from Dr Mushui Dai), Rps14 and Rps19 (Santa Cruz Biotechnology, Santa Cruz, CA), rabbit polyclonal Ab for mouse Mdm2 (raised against mouse Mdm2 peptide EQTPLSQESDDYSOPSTSSS, made by Yenzym, San Francisco, CA, used for IP), human MDM2 (Ab-1, Calbiochem, San Diego, CA), p21 (BD Biosciences, San Jose, CA), and $\beta$-actin (Sigma).

\section{Flow cytometry}

For surface staining, cells were incubated with the indicated antibodies in staining buffer (HBSS with $2 \% \mathrm{FBS}$ ) for $20 \mathrm{~min}$ at $4^{\circ} \mathrm{C}$. The following antibodies were purchased from eBioscience, San Diego, CA: Fluorescein isothiocyanate (FITC)-conjugated anti-CD3e (clone 145-2C11), anti-CD4 (GK1.5), antiCD8a (53-6.7), anti-CD16/CD32 (93), anti-CD43 (eBioR2-60), anti-CD45.1 (A20), and anti-CD45.2 (104); phycoerythrin (PE)-conjugated anti-CD3e (M1/69), anti-B220 (RA3-6B2), anti-Mac-1 (M1/70), anti-Gr-1 (RB6-8C5), anti-Ter119 (TER-119), and anti-CD45.2 (104); PE-Cy7-conjugated anti-CD4 (RM4-5), and anti-B220 (RA3-6B2); allophycocyanin (APC)-conjugated anti-CD8a (53-6.7), anti-CD45.1 (A20), anti-CD48 (HM48-1), anti-CD71 (R17217), and anti-Gr-1 (RB6-8C5); APC-eFluor780-conjugated anti-CD117 (c-Kit, clone 2B8); and eFluor660-conjugated anti-CD34 (RAM34). The following antibodies were purchased from BD Biosciences: PerCP-Cy5.5-conjugated anti-B220 (RA3-6B2), and antiMac-1 (M1/70); PE-Cy7-conjugated anti-CD45.2 (104), and anti-Ly-6A/E (Sca-1, clone D7). Lineage markers included B220 (B cells), CD3 (T cells), Gr-1 (granulocyte), Mac-1 (myeloid cells), and Ter119 (erythrocytes). PerCP-Cy5.5-conjugated anti-CD150 Ab (clone TC15-12F12.2) was purchased from BioLegend, San Diego, CA, and FITC-conjugated Annexin V and FITC-conjugated anti-BrdU antibody were from BD Biosciences. All FACS analyses were performed on an LSR II flow cytometer (BD Biosciences), and data were analyzed with FlowJo software (Tang et al., 2012).

\section{Transplantation assays}

6-8-week-old C57BL/6 Ly5.2 (CD45.1) recipient mice were lethally irradiated with a ${ }^{137} \mathrm{Cs}$ source delivering 170 rad per min for a total dose of 1100 rads. Given numbers of fetal liver cells from E14.5 embryos (CD45.2) were either injected alone or mixed with recipient-type (CD45.1) competitive BM cells. The cells were injected into recipients through the tail vein within $24 \mathrm{hr}$ after irradiation. Reconstitutions were measured by flow cytometry of peripheral blood at the time points indicated (Chen et al., 2009; Tang et al., 2012).

\section{Immunohistochemistry}

Immunohistochemical staining was performed on the DAKO Autostainer (DAKO, Carpinteria, CA) using diaminobenzadine $(\mathrm{DAB})$ as the chromogen. After dewaxing and rehydration, serial sections 
were labeled with p53 (CM5p, Leica Microsystems), after 10 mM citrate buffer, pH6 microwave epitope retrieval. $\mathrm{LSAB}+(\mathrm{DAKO})$ was employed as the detection system. Appropriate negative (no primary $\mathrm{Ab})$ and positive controls were stained in parallel.

\section{In vitro ubiquitylation assay}

MEF cells treated with MG132 for $4 \mathrm{hr}$ were lysed and IP with Mdm2 Ab. The Mdm2/Mdm4-p53 complex were then incubated with $10 \mu \mathrm{g}$ ubiquitin, $375 \mathrm{ng}$ UBE1, $150 \mathrm{ng}$ Ubc5Hb (Boston Biochem, Cambridge, $\mathrm{MA})$, and $30 \mu$ reaction buffer $(50 \mathrm{mM}$ Tris $\mathrm{pH} 7.5,2.5 \mathrm{mM} \mathrm{MgCl}, 15 \mathrm{mM} \mathrm{KCl}, 1 \mathrm{mMDTT}, 0.01 \%$ Triton-X-100, $1 \%$ glycerol) in the presence of $4 \mathrm{mM}$ ATP. The mixture was incubated at $37^{\circ} \mathrm{C}$ for 60 min with continuous vortexing, and subjected to IB after boiling in SDS sample buffer (Cheng et al., 2009).

\section{Ribosomal profiling}

The profiling was conducted as described (Zhu et al., 2012) with modifications. Briefly, MEFs were treated with cycloheximide $(100 \mu \mathrm{g} / \mathrm{ml})$ in growth medium for $30 \mathrm{~min}$ at $37^{\circ} \mathrm{C}$. Cells were washed with PBS containing cycloheximide and then lysed in extraction buffer containing $20 \mathrm{mM} \mathrm{HEPES} \mathrm{(pH} \mathrm{7.5),}$ $5 \mathrm{mM} \mathrm{MgCl}$, $150 \mathrm{mM} \mathrm{KCl}, 100 \mu \mathrm{g} / \mathrm{ml}$ cycloheximide, $1 \mathrm{mM}$ DTT, 0.5\% Triton-X 100, 0.5\% Sodium deoxycholate, and RNase inhibitor. Extracts were spun for $10 \mathrm{~s}$ to pellet nuclei and then cleared by centrifugation at $10,000 \times \mathrm{g}$ for $10 \mathrm{~min}$ at $4^{\circ} \mathrm{C}$. The cytoplasmic extracts were loaded onto $4.5 \mathrm{ml}$ sucrose gradients (10\%-50\%) buffered in 20 mM HEPES (pH 7.5), $100 \mathrm{mM} \mathrm{KCl}, 5 \mathrm{mM} \mathrm{MgCl} 2,1 \mathrm{mM}$ DTT. Gradients were subjected to ultra-centrifugation using a Beckman SW50.1 Rotor at 40,000 rpm for $100 \mathrm{~min}$ at $4^{\circ} \mathrm{C}$. Gradients were then fractionated measured by optical density at $254 \mathrm{~nm}$.

\section{rRNA processing}

MEF cells on $60 \mathrm{~mm}$ dish were starved of methionine in methionine-free medium for $30 \mathrm{~min}$ and then pulse-labeled for $30 \mathrm{~min}$ in $1 \mathrm{ml}$ medium containing $50 \mu \mathrm{Ci}$ of L-[methyl- $\left.{ }^{3} \mathrm{H}\right]$-methionine (MP Biochemicals, Santa Ana, CA). After rinsing with $10 \times$ methonine $(0.3 \mathrm{mg} / \mathrm{ml})$ medium, cells were incubated in $10 \times$ methonine medium for indicated time periods. Total RNA was isolated using RNeasy kit (Qiagen, Valencia, CA) and subjected to 1\% Agarose formaldehyde gel electrophoresis and then transferred on Nylon membrane. The membrane was dried and sprayed with EN3HANCE (PerkinElmer, Waltham, MA) and then exposed at $-80^{\circ} \mathrm{C}$ for a week (Itahana et al., 2003).

\section{In vivo ubiquitylation assay}

Human lung H1299 cells were transiently transfected with various plasmids. Cells were harvested $24 \mathrm{hr}$ post transfection after last $4 \mathrm{hr}$ MG132 treatment and split into two aliquots with one for direct Western blotting analysis and the other for in vivo ubiquitylation assay as described (Gu et al., 2007). Briefly, cell pellets were lysed and incubated with Ni-NTA beads (Qiagen) at room temperature for 4 hr. Beads were then washed and incubated with elution buffer at room temperature for $20 \mathrm{~min}$. The eluted proteins were analyzed by Western blotting.

\section{Lentivirus-based shRNA}

The sequences of scrambled control siRNA and RPS27L siRNA have been described (Xiong et al., 2011). Short hairpins targeting mouse Rpl11 (targeting sequence: 5'-CGG GAG TAT GAG TTG CGG AAA-3') or Rpl5 (targeting sequence: 5'-CCC TCA TAG TAC CAA ACG ATT-3') was cloned into pLKO.1-puro vector. Two additional Rpl5-silencing clones (TRCN0000104427 and TRCN0000104429) were purchased from Thermo Fisher Scientific, Waltham, MA. Lentiviral particles were produced by University of Michigan Vector Core.

\section{Metaphase preparation}

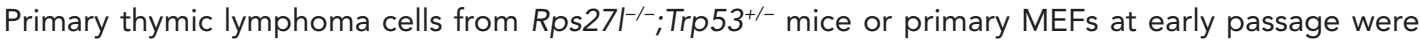
treated with $0.2 \mu \mathrm{g} / \mathrm{ml}$ KaryoMAX colcemid solution (Life Technologies) for $2 \mathrm{hr}$ before harvesting for metaphase preparation. Metaphase spreads were stained by incubation in 4\% KaryoMAX Giemsa solution (Life Technologies) for $15 \mathrm{~min}$, followed by observation under a light microscope. Chromosome numbers were counted (Wu et al., 2011).

\section{Real-time PCR}

Total RNA was isolated from MEF cells with Trizol reagent (Life Technologies). Complementary DNA was made from RNA with Superscript III (Life Technologies). Real-time PCR was performed on a 7500 Real 
Time PCR system (Life Technologies). The cycling program was set as follows: $50^{\circ} \mathrm{C} 2 \mathrm{~min}, 95^{\circ} \mathrm{C} 10 \mathrm{~min}$ for the PCR initial activation and 45 cycles of denaturation at $95^{\circ} \mathrm{C}$ for $15 \mathrm{~s}$, annealing and extension at $60^{\circ} \mathrm{C}$ for $1 \mathrm{~min}$. The sequences of p53, Mdm2, p21, Mdm4, 45S rRNA, and GAPDH are as follows: p53-RT-F: 5'-GAG AGT ATT TCA CCC TCA AGA TCC G-3', p53-RT-R: 5'-CCC CAC TTT CTT GAC CAT TGT TT-3'; Mdm2-RT-F: 5'-GAT GAG GAT GAT GAG GTC TAT CGG-3', Mdm2-RT-R: 5'-TCT GGA AGC CAG TTC TCA CGA A-3'; p21-RT-F: 5'-ACT TCC TCT GCC CTG CTG CA-3', p21-RT-R: 5'-CGC TTG GAG TGA TAG AAA TCT GTC A-3'; Mdm4-RT-F: 5'-TTT ACA GAC AAA TCA GGA TAT AGG TA-3', Mdm4-RT-R: 5'-GTA CAC TGC CAC TCA TCC TCA-3'; 45S-F: 5'-ACA CGC TGT CCT TTC CCT ATT AAC ACT AAA-3', 45S-R: 5'-AGT AAA AAG AAT AGG CTG GAC AAG CAA AAC-3'; GAPDH-F: 5'GCC GCC TGG AGA AAC CTG CC-3', GAPDH-R: 5'-GGT GGA AGA GTG GGA GTT GC-3' (Poortinga et al., 2004).

For quantitative measurement of Trp53 dosage, genomic DNA were isolated from MEFs and amplified with the following primer sets: p53-del-F2: 5'-CCT GAT CGT TAC TCG GCT TGT C-3', p53-del-R2: 5'-CAA CTG CAC AGG GCA CGT CT-3'; p53-del-F4: 5'-GGC TTC TGA CTT ATT CTT GCT CTT A-3', p53-del-R4: 5'-AGA CCT CGG GTG GCT CAT AA-3'; p53-del-F5: 5'-GAG GTA GGG AGC GAC TTC ACC-3', p53-del-R5: 5'-GGT AAG GAT AGG TCG GCG GTT-3'; GAPDH-F: 5'-GTA TGA CTC CAC TCA CGG CAA A-3', GAPDH-R: 5'-GGT CTC GCT CCT GGA AGA TG-3'.

\section{[35S]-methionine metabolic labeling}

For determination of p53 protein synthesis, MEF cells were treated for $1 \mathrm{hr}$ in methionine-free and cysteine-free DMEM, containing 10\% dialyzed FCS and $50 \mu \mathrm{M} \mathrm{MG132.} \mathrm{Cells} \mathrm{were} \mathrm{then} \mathrm{labeled} \mathrm{with}$

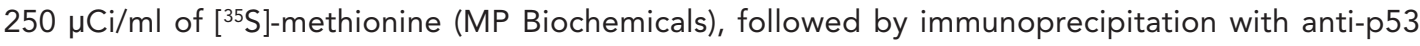
antibody (1C12). Immunoprecipitates, along with whole cell extract, were then subjected to SDSPAGE and autoradiography (Wang et al., 2009b).

For determination of global nascent protein synthesis, MEF cells on $60 \mathrm{~mm}$ dish were starved in methionine-free and cysteine-free DMEM with dialyzed FCS for $30 \mathrm{~min}$ and then pulse-labeled with $1 \mathrm{ml}\left[{ }^{35} \mathrm{~S}\right]$-methionine $(200 \mu \mathrm{Ci} / \mathrm{ml})$ for $1 \mathrm{hr}$. After PBS washing, cells were lysed in $0.5 \% \mathrm{NP}-40$ buffer. Equal amounts of protein extracts were precipitated with $20 \%$ ice-cold TCA for $30 \mathrm{~min}$ on ice, and dissolved in $0.1 \mathrm{~N} \mathrm{NaOH}$. Total $\left.{ }^{35} \mathrm{~S}\right]$-methionine incorporation was measured with a liquid scintillation counter and plotted as counts per min/ $\mu \mathrm{g}$ protein. Equal amounts of protein were also subjected to SDS-PAGE and autoradiography (Lindstrom and Zhang, 2008).

\section{Trp53 exons amplification}

To determine the deletion of Trp53 wt allele, genomice DNA were isolated and amplified with the following primer sets: Exon-1-F: 5'-ATC GGT TTC CAC CCA TTT TG-3', Exon-1-R: 5'-ATA CAC TCC CGT TCA TCC CG-3'; Exon-2-F: 5'-TAC CTC TGC TCA GCC CCC G-3', Exon-2-R: 5'-TTA CAG ACA CCC AAC ACC ATA CCA-3'; Exon-3-F: 5'-GCA GGG TCT CAG AAG TTT GAG G-3', Exon-3-R: 5'-GTG GAT GGG ACA AAG AAG AAC C-3'; Exon-4-F: 5'-TTG GGC TTT GGT GTT GGG-3', Exon-4-R: 5'-AGG CTG AAG AGG AAC CCC C-3'; Exon-5-F: 5'-CGG GGA GTT GTC TTT CGT GT-3', Exon-5-R: 5'-TAA GAG CAA GAA TAA GTC AGA AGC C-3'; Exon-6-F: GTA AGC CCT CAA CAC CGC C-3', Exon6-R: 5'-GAC TCA GCG TCT CTA TTT CCC G-3'; Exon-7-F: 5'-TCC AGC AGG TGT GCC GAA-3', Exon-7-R: 5'-AAC CCC GAG AAG CCA CAG A-3'; Exon-8-F: 5'-TCT GTG GCT TCT CGG GGT TC-3', Exon-8-R: 5'-GGA AGG AGA GAG CAA GAG GTG AC-3'; Exon-9-F: 5'-CGG AGG AGC CTG TTG AGC TT-3', Exon-9-R: 5'-CAG CCT CAG AGC ATG AGC TC-3'; Exon-10-11-F: GAG CCA GCT TAA GTT GGG AAC-3', Exon-10-11-R: 5'-GAC AGC AAG GAG AGG GGG-3'.

\section{Statistical analysis}

The two-tailed Student's $t$ test was used for the comparison of parameters between groups. Survival analysis was performed by Kaplan-Meier analysis. Statistical significance was determined as $p<0.05$.

\section{Acknowledgements}

We would like to thank Drs Jiandong Chen, Aart G Jochemsen, Yanping Zhang, Hua Lu, Ruiwen Zhang, and Mushui Dai for providing antibodies; Dr Janine Maddock for her help in setting up ribosomal profiling experiment. We also thank Dr Yuan Zhu for providing us Trp53-deficient mice and discussions. This work is supported by the $\mathrm{NCl}$ grants (CA118762, CA156744, CA170995 and CA171277) to YS and Susan G Komen for the Cure PDF Grant (PDF12230424) to YZ. 


\section{Additional information}

\begin{tabular}{lll}
$\begin{array}{l}\text { Funding } \\
\text { Funder }\end{array}$ & Grant reference number & Author \\
\hline National Cancer Institute & R01 CA118762 & $\begin{array}{l}\text { Xiufang Xiong, } \\
\text { Yongchao Zhao, Yi Sun }\end{array}$ \\
\hline National Cancer Institute & R01 CA171277 & $\begin{array}{l}\text { Xiufang Xiong, } \\
\text { Yongchao Zhao, Yi Sun }\end{array}$
\end{tabular}

The funder had no role in study design, data collection and interpretation, or the decision to submit the work for publication.

Author contributions

$X X, Y Z$, Conception and design, Acquisition of data, Analysis and interpretation of data; FT, DW, DT, $\mathrm{XW}$, Acquisition of data, Analysis and interpretation of data; YL, PZ, Conception and design, Analysis and interpretation of data; YS, Conception and design, Analysis and interpretation of data, Drafting or revising the article

Ethics

Animal experimentation: All the animal procedures were approved by the University of Michigan Committee on Use and Care of Animals (Protocol \# PRO00004764). Animal care was provided in accordance with the principles and procedures outlined in the National Research Council Guide for the Care and Use of Laboratory Animals.

\section{References}

Abbas HA, Maccio DR, Coskun S, Jackson JG, Hazen AL, Sills TM, You MJ, Hirschi KK, Lozano G. 2010. Mdm2 is required for survival of hematopoietic stem cells/progenitors via dampening of ROS-induced p53 activity. Cell Stem Cell 7:606-617. doi: 10.1016/j.stem.2010.09.013.

Alt JR, Greiner TC, Cleveland JL, Eischen CM. 2003. Mdm2 haplo-insufficiency profoundly inhibits Myc-induced lymphomagenesis. The EMBO Journal 22:1442-1450. doi: 10.1093/emboj/cdg133.

Anderson SJ, Lauritsen JP, Hartman MG, Foushee AM, Lefebvre JM, Shinton SA, Gerhardt B, Hardy RR, Oravecz T, Wiest DL. 2007. Ablation of ribosomal protein L22 selectively impairs alphabeta T cell development by activation of a p53-dependent checkpoint. Immunity 26:759-772. doi: 10.1016/j.immuni.2007.04.012.

Armstrong JF, Kaufman MH, Harrison DJ, Clarke AR. 1995. High-frequency developmental abnormalities in p53-deficient mice. Current Biology 5:931-936. doi: 10.1016/S0960-9822(95)00183-7.

Barkic M, Crnomarkovic S, Grabusic K, Bogetic I, Panic L, Tamarut S, Cokaric M, Jeric I, Vidak S, Volarevic S. 2009. The p53 tumor suppressor causes congenital malformations in Rpl24-deficient mice and promotes their survival. Molecular and Cellular Biology 29:2489-2504. doi: 10.1128/MCB.01588-08.

Barlow JL, Drynan LF, Hewett DR, Holmes LR, Lorenzo-Abalde S, Lane AL, Jolin HE, Pannell R, Middleton AJ, Wong SH, Warren AJ, Wainscoat JS, Boultwood J, McKenzie AN. 2010. A p53-dependent mechanism underlies macrocytic anemia in a mouse model of human 5q- syndrome. Nature Medicine 16:59-66. doi: 10.1038/ nm.2063.

Bhat KP, Itahana K, Jin A, Zhang Y. 2004. Essential role of ribosomal protein L11 in mediating growth inhibitioninduced p53 activation. The EMBO Journal 23:2402-2412. doi: 10.1038/sj.emboj.7600247.

Bursac S, Brdovcak MC, Donati G, Volarevic S. 2014. Activation of the tumor suppressor p53 upon impairment of ribosome biogenesis. Biochimica et Biophysica Acta 1842:817-830. doi: 10.1016/j.bbadis.2013.08.014.

Bursac S, Brdovcak MC, Pfannkuchen M, Orsolic I, Golomb L, Zhu Y, Katz C, Daftuar L, Grabusic K, Vukelic I, Filić V, Oren M, Prives C, Volarevic S. 2012. Mutual protection of ribosomal proteins L5 and L11 from degradation is essential for p53 activation upon ribosomal biogenesis stress. Proceedings of the National Academy of Sciences of USA 109:20467-20472. doi: 10.1073/pnas.1218535109.

Chen C, Liu Y, Zheng P. 2009. mTOR regulation and therapeutic rejuvenation of aging hematopoietic stem cells. Science Signaling 2:ra75. doi: 10.1126/scisignal.2000559.

Chen D, Zhang Z, Li M, Wang W, Li Y, Rayburn ER, Hill DL, Wang H, Zhang R. 2007. Ribosomal protein S7 as a novel modulator of p53-MDM2 interaction: binding to MDM2, stabilization of p53 protein, and activation of p53 function. Oncogene 26:5029-5037. doi: 10.1038/sj.onc.1210327.

Cheng $\mathrm{Q}$, Chen L, Li Z, Lane WS, Chen J. 2009. ATM activates p53 by regulating MDM2 oligomerization and E3 processivity. The EMBO Journal 28:3857-3867. doi: 10.1038/emboj.2009.294.

Cui D, Li L, Lou H, Sun H, Ngai SM, Shao G, Tang J. 2014. The ribosomal protein S26 regulates p53 activity in response to DNA damage. Oncogene 33:2225-2235. doi: 10.1038/onc.2013.170.

Daftuar L, Zhu Y, Jacq X, Prives C. 2013. Ribosomal proteins RPL37, RPS15 and RPS20 regulate the Mdm2-p53Mdmx network. PLOS ONE 8:e68667. doi: 10.1371/journal.pone.0068667. 
Dai MS, Lu H. 2004. Inhibition of MDM2-mediated p53 ubiquitination and degradation by ribosomal protein L5. The Journal of Biological Chemistry 279:44475-44482. doi: 10.1074/jbc.M403722200.

Dai MS, Zeng SX, Jin Y, Sun XX, David L, Lu H. 2004. Ribosomal protein L23 activates p53 by inhibiting MDM2 function in response to ribosomal perturbation but not to translation inhibition. Molecular and Cellular Biology 24:7654-7668. doi: 10.1128/MCB.24.17.7654-7668.2004.

de Graaf P, Little NA, Ramos YF, Meulmeester E, Letteboer SJ, Jochemsen AG. 2003. Hdmx protein stability is regulated by the ubiquitin ligase activity of Mdm2. The Journal of Biological Chemistry 278:38315-38324. doi: 10.1074/jbc.M213034200.

de Rozieres S, Maya R, Oren M, Lozano G. 2000. The loss of mdm2 induces p53-mediated apoptosis. Oncogene 19:1691-1697. doi: 10.1038/sj.onc.1203468.

Fang S, Jensen JP, Ludwig RL, Vousden KH, Weissman AM. 2000. Mdm2 is a RING finger-dependent ubiquitin protein ligase for itself and p53. The Journal of Biological Chemistry 275:8945-8951. doi: 10.1074/jbc.275.12.8945.

Finch RA, Donoviel DB, Potter D, Shi M, Fan A, Freed DD, Wang CY, Zambrowicz BP, Ramirez-Solis R, Sands AT, Zhang N. 2002. $m d m x$ is a negative regulator of p53 activity in vivo. Cancer Research 62:3221-3225.

Francoz S, Froment P, Bogaerts S, De Clercq S, Maetens M, Doumont G, Bellefroid E, Marine JC. 2006. Mdm4 and $\mathrm{Mdm} 2$ cooperate to inhibit p53 activity in proliferating and quiescent cells in vivo. Proceedings of the National Academy of Sciences of USA 103:3232-3237. doi: 10.1073/pnas.0508476103.

Fumagalli S, Di Cara A, Neb-Gulati A, Natt F, Schwemberger S, Hall J, Babcock GF, Bernardi R, Pandolfi PP, Thomas G. 2009. Absence of nucleolar disruption after impairment of $40 \mathrm{~S}$ ribosome biogenesis reveals an rpL11-translation-dependent mechanism of p53 induction. Nature Cell Biology 11:501-508. doi: 10.1038/ ncb1858.

Garcia D, Warr MR, Martins CP, Brown Swigart L, Passegue E, Evan Gl. 2011. Validation of MdmX as a therapeutic target for reactivating p53 in tumors. Genes \& Development 25:1746-1757. doi: 10.1101/gad.16722111.

Giaccia AJ, Kastan MB. 1998. The complexity of p53 modulation: emerging patterns from divergent signals. Genes \& Development 12:2973-2983. doi: 10.1101/gad.12.19.2973.

Gilkes DM, Chen L, Chen J. 2006. MDMX regulation of p53 response to ribosomal stress. The EMBO Journal 25:5614-5625. doi: 10.1038/sj.emboj.7601424.

Golomb L, Volarevic S, Oren M. 2014. p53 and ribosome biogenesis stress: The essentials. FEBS Letters 588:2571-2579. doi: 10.1016/j.febslet.2014.04.014.

Greenblatt MS, Bennett WP, Hollstein M, Harris CC. 1994. Mutations in the p53 tumor suppressor gene: clues to cancer etiology and molecular pathogenesis. Cancer Research 54:4855-4878.

Gu Q, Tan M, Sun Y. 2007. SAG/ROC2/Rbx2 is a novel activator protein-1 target that promotes c-Jun degradation and inhibits 12-O-tetradecanoylphorbol-13-acetate-induced neoplastic transformation. Cancer Research 67:3616-3625. doi: 10.1158/0008-5472.CAN-06-4020.

Haupt Y, Maya R, Kazaz A, Oren M. 1997. Mdm2 promotes the rapid degradation of p53. Nature 387:296-299. doi: $10.1038 / 387296 a 0$.

He H, Sun Y. 2007. Ribosomal protein S27L is a direct p53 target that regulates apoptosis. Oncogene 26: 2707-2716. doi: 10.1038/sj.onc.1210073.

Honda R, Tanaka H, Yasuda H. 1997. Oncoprotein MDM2 is a ubiquitin ligase E3 for tumor suppressor p53. FEBS Letters 420:25-27. doi: 10.1016/S0014-5793(97)01480-4.

Honda R, Yasuda H. 2000. Activity of MDM2, a ubiquitin ligase, toward p53 or itself is dependent on the RING finger domain of the ligase. Oncogene 19:1473-1476. doi: 10.1038/sj.onc.1203464.

Huang CJ, Yang SH, Lee CL, Cheng YC, Tai SY, Chien CC. 2013. Ribosomal protein S27-like in colorectal cancer: a candidate for predicting prognoses. PLOS ONE 8:e67043. doi: 10.1371/journal.pone.0067043.

Huang L, Yan Z, Liao X, Li Y, Yang J, Wang ZG, Zuo Y, Kawai H, Shadfan M, Ganapathy S, Yuan ZM. 2011. The p53 inhibitors MDM2/MDMX complex is required for control of p53 activity in vivo. Proceedings of the National Academy of Sciences of USA 108:12001-12006. doi: 10.1073/pnas.1102309108.

Itahana K, Bhat KP, Jin A, Itahana Y, Hawke D, Kobayashi R, Zhang Y. 2003. Tumor suppressor ARF degrades B23, a nucleolar protein involved in ribosome biogenesis and cell proliferation. Molecular Cell 12:1151-1164. doi: 10.1016/S1097-2765(03)00431-3.

Itahana K, Mao H, Jin A, Itahana Y, Clegg HV, Lindstrom MS, Bhat KP, Godfrey VL, Evan Gl, Zhang Y. 2007. Targeted inactivation of Mdm2 RING finger E3 ubiquitin ligase activity in the mouse reveals mechanistic insights into p53 regulation. Cancer Cell 12:355-366. doi: 10.1016/j.ccr.2007.09.007.

Jacks T, Remington L, Williams BO, Schmitt EM, Halachmi S, Bronson RT, Weinberg RA. 1994. Tumor spectrum analysis in p53-mutant mice. Current Biology 4:1-7. doi: 10.1016/S0960-9822(00)00002-6.

Jin A, Itahana K, O'Keefe K, Zhang Y. 2004. Inhibition of HDM2 and activation of p53 by ribosomal protein L23. Molecular and Cellular Biology 24:7669-7680. doi: 10.1128/MCB.24.17.7669-7680.2004.

Jones NC, Lynn ML, Gaudenz K, Sakai D, Aoto K, Rey JP, Glynn EF, Ellington L, Du C, Dixon J, Dixon MJ, Trainor PA. 2008. Prevention of the neurocristopathy Treacher Collins syndrome through inhibition of p53 function. Nature Medicine 14:125-133. doi: 10.1038/nm1725.

Jones SN, Roe AE, Donehower LA, Bradley A. 1995. Rescue of embryonic lethality in Mdm2-deficient mice by absence of p53. Nature 378:206-208. doi: 10.1038/378206a0.

Kawai H, Lopez-Pajares V, Kim MM, Wiederschain D, Yuan ZM. 2007. RING domain-mediated interaction is a requirement for MDM2's E3 ligase activity. Cancer Research 67:6026-6030. doi: 10.1158/0008-5472. CAN-07-1313.

Kawai H, Wiederschain D, Kitao H, Stuart J, Tsai KK, Yuan ZM. 2003. DNA damage-induced MDMX degradation is mediated by MDM2. The Journal of Biological Chemistry 278:45946-45953. doi: 10.1074/jbc.M308295200. 
Kibe R, Zhang S, Guo D, Marrero L, Tsien F, Rodriguez P, Khan S, Zieske A, Huang J, Li W, Durum SK, Iwakuma T, Cui Y. 2012. IL-7Ralpha deficiency in p53null mice exacerbates thymocyte telomere erosion and lymphomagenesis. Cell Death and Differentiation 19:1139-1151. doi: 10.1038/cdd.2011.203.

Ko LJ, Prives C. 1996. p53: puzzle and paradigm. Genes \& Development 10:1054-1072. doi: 10.1101/ gad.10.9.1054.

Kostic M, Matt T, Martinez-Yamout MA, Dyson HJ, Wright PE. 2006. Solution structure of the Hdm2 C2H2C4 RING, a domain critical for ubiquitination of p53. Journal of Molecular Biology 363:433-450. doi: 10.1016/j. jmb.2006.08.027.

Kruse JP, Gu W. 2009. Modes of p53 regulation. Cell 137:609-622. doi: 10.1016/j.cell.2009.04.050.

Kubbutat MH, Jones SN, Vousden KH. 1997. Regulation of p53 stability by Mdm2. Nature 387:299-303. doi: 10.1038/387299a0.

Levine AJ. 1997. p53, the cellular gatekeeper for growth and division. Cell 88:323-331. doi: 10.1016/ S0092-8674(00)81871-1.

Levine AJ, Oren M. 2009. The first 30 years of p53: growing ever more complex. Nature Reviews Cancer 9:749-758. doi: 10.1038/nrc2723.

Li J, Tan J, Zhuang L, Banerjee B, Yang X, Chau JF, Lee PL, Hande MP, Li B, Yu Q. 2007. Ribosomal protein S27-like, a p53-inducible modulator of cell fate in response to genotoxic stress. Cancer Research 67: 11317-11326. doi: 10.1158/0008-5472.CAN-07-1088.

Linares LK, Hengstermann A, Ciechanover A, Muller S, Scheffner M. 2003. HdmX stimulates Hdm2-mediated ubiquitination and degradation of p53. Proceedings of the National Academy of Sciences of USA 100:12009-12014. doi: 10.1073/pnas.2030930100.

Lindstrom MS, Zhang Y. 2008. Ribosomal protein S9 is a novel B23/NPM-binding protein required for normal cell proliferation. The Journal of Biological Chemistry 283:15568-15576. doi: 10.1074/jbc.M801151200.

Lohrum MA, Ludwig RL, Kubbutat MH, Hanlon M, Vousden KH. 2003. Regulation of HDM2 activity by the ribosomal protein L11. Cancer Cell 3:577-587. doi: 10.1016/S1535-6108(03)00134-X.

Macias E, Jin A, Deisenroth C, Bhat K, Mao H, Lindstrom MS, Zhang Y. 2010. An ARF-independent c-MYCactivated tumor suppression pathway mediated by ribosomal protein-Mdm2 Interaction. Cancer Cell 18:231-243. doi: 10.1016/j.ccr.2010.08.007.

McGowan KA, Li JZ, Park CY, Beaudry V, Tabor HK, Sabnis AJ, Zhang W, Fuchs H, de Angelis MH, Myers RM, Attardi LD, Barsh GS. 2008. Ribosomal mutations cause p53-mediated dark skin and pleiotropic effects. Nature Genetics 40:963-970. doi: 10.1038/ng.188.

Mendrysa SM, O'Leary KA, McElwee MK, Michalowski J, Eisenman RN, Powell DA, Perry ME. 2006. Tumor suppression and normal aging in mice with constitutively high p53 activity. Genes \& Development 20:16-21. doi: 10.1101/gad.1378506.

Migliorini D, Lazzerini Denchi E, Danovi D, Jochemsen A, Capillo M, Gobbi A, Helin K, Pelicci PG, Marine JC. 2002. Mdm4 (Mdmx) regulates p53-induced growth arrest and neuronal cell death during early embryonic mouse development. Molecular and Cellular Biology 22:5527-5538. doi: 10.1128/MCB.22.15.5527-5538.2002.

Montes de Oca Luna R, Wagner DS, Lozano G. 1995. Rescue of early embryonic lethality in mdm2-deficient mice by deletion of p53. Nature 378:203-206. doi: 10.1038/378203a0.

Ofir-Rosenfeld Y, Boggs K, Michael D, Kastan MB, Oren M. 2008. Mdm2 regulates p53 mRNA translation through inhibitory interactions with ribosomal protein L26. Molecular Cell 32:180-189. doi: 10.1016/j.molcel.2008.08.031.

Pan Y, Chen J. 2003. MDM2 promotes ubiquitination and degradation of MDMX. Molecular and Cellular Biology 23:5113-5121. doi: 10.1128/MCB.23.15.5113-5121.2003.

Panic L, Tamarut S, Sticker-Jantscheff M, Barkic M, Solter D, Uzelac M, Grabusic K, Volarevic S. 2006. Ribosomal protein S6 gene haploinsufficiency is associated with activation of a p53-dependent checkpoint during gastrulation. Molecular and Cellular Biology 26:8880-8891. doi: 10.1128/MCB.00751-06.

Pant V, Xiong S, Iwakuma T, Quintas-Cardama A, Lozano G. 2011. Heterodimerization of Mdm2 and Mdm4 is critical for regulating p53 activity during embryogenesis but dispensable for p53 and Mdm2 stability. Proceedings of the National Academy of Sciences of USA 108:11995-12000. doi: 10.1073/pnas.1102241108.

Parant J, Chavez-Reyes A, Little NA, Yan W, Reinke V, Jochemsen AG, Lozano G. 2001. Rescue of embryonic lethality in Mdm4-null mice by loss of Trp53 suggests a nonoverlapping pathway with MDM2 to regulate p53. Nature Genetics 29:92-95. doi: 10.1038/ng714.

Poortinga G, Hannan KM, Snelling H, Walkley CR, Jenkins A, Sharkey K, Wall M, Brandenburger Y, Palatsides M, Pearson RB, McArthur GA, Hannan RD. 2004. MAD1 and c-MYC regulate UBF and rDNA transcription during granulocyte differentiation. The EMBO Journal 23:3325-3335. doi: 10.1038/sj.emboj.7600335.

Poyurovsky MV, Priest C, Kentsis A, Borden KL, Pan ZQ, Pavletich N, Prives C. 2007. The Mdm2 RING domain $\mathrm{C}$-terminus is required for supramolecular assembly and ubiquitin ligase activity. The EMBO Journal 26:90-101. doi: 10.1038/sj.emboj.7601465.

Sah VP, Attardi LD, Mulligan GJ, Williams BO, Bronson RT, Jacks T. 1995. A subset of p53-deficient embryos exhibit exencephaly. Nature Genetics 10:175-180. doi: 10.1038/ng0695-175.

Sasaki M, Kawahara K, Nishio M, Mimori K, Kogo R, Hamada K, Itoh B, Wang J, Komatsu Y, Yang YR, Hikasa H, Horie Y, Yamashita T, Kamijo T, Zhang Y, Zhu Y, Prives C, Nakano T, Mak TW, Sasaki T, Maehama T, Mori M, Suzuki A. 2011. Regulation of the MDM2-P53 pathway and tumor growth by PICT1 via nucleolar RPL11. Nature Medicine 17:944-951. doi: 10.1038/nm.2392.

Sharp DA, Kratowicz SA, Sank MJ, George DL. 1999. Stabilization of the MDM2 oncoprotein by interaction with the structurally related MDMX protein. The Journal of Biological Chemistry 274:38189-38196. doi: 10.1074/ jbc.274.53.38189. 
Shvarts A, Steegenga WT, Riteco N, van Laar T, Dekker P, Bazuine M, van Ham RC, van der Houven van Oordt W, Hateboer G, van der Eb AJ, Jochemsen AG. 1996. MDMX: a novel p53-binding protein with some functional properties of MDM2. The EMBO Journal 15:5349-5357.

Sulic S, Panic L, Barkic M, Mercep M, Uzelac M, Volarevic S. 2005. Inactivation of S6 ribosomal protein gene in T lymphocytes activates a p53-dependent checkpoint response. Genes \& Development 19:3070-3082. doi: $10.1101 /$ gad.359305.

Sun XX, DeVine T, Challagundla KB, Dai MS. 2011. Interplay between ribosomal protein S27a and MDM2 protein in p53 activation in response to ribosomal stress. The Journal of Biological Chemistry 286:22730-22741. doi: 10.1074/jbc.M111.223651.

Tan M, Davis SW, Saunders TL, Zhu Y, Sun Y. 2009. RBX1/ROC1 disruption results in early embryonic lethality due to proliferation failure, partially rescued by simultaneous loss of p27. Proceedings of the National Academy of Sciences of USA 106:6203-6208. doi: 10.1073/pnas.0812425106.

Tang F, Wu Q, Ikenoue T, Guan KL, Liu Y, Zheng P. 2012. A critical role for Rictor in T lymphopoiesis. The Journal of Immunology 189:1850-1857. doi: 10.4049/jimmunol.1201057.

Tanimura S, Ohtsuka S, Mitsui K, Shirouzu K, Yoshimura A, Ohtsubo M. 1999. MDM2 interacts with MDMX through their RING finger domains. FEBS Letters 447:5-9. doi: 10.1016/S0014-5793(99)00254-9.

Terzian T, Dumble M, Arbab F, Thaller C, Donehower LA, Lozano G, Justice MJ, Roop DR, Box NF. 2011. Rpl27a mutation in the sooty foot ataxia mouse phenocopies high p53 mouse models. The Journal of Pathology 224:540-552. doi: 10.1002/path.2891.

Terzian T, Wang Y, Van Pelt CS, Box NF, Travis EL, Lozano G. 2007. Haploinsufficiency of Mdm2 and Mdm4 in tumorigenesis and development. Molecular and Cellular Biology 27:5479-5485. doi: 10.1128/MCB.00555-06.

Uldrijan S, Pannekoek WJ, Vousden KH. 2007. An essential function of the extreme C-terminus of MDM2 can be provided by MDMX. The EMBO Journal 26:102-112. doi: 10.1038/sj.emboj.7601469.

Vogelstein B, Lane D, Levine AJ. 2000. Surfing the p53 network. Nature 408:307-310. doi: 10.1038/35042675.

Volarevic S, Stewart MJ, Ledermann B, Zilberman F, Terracciano L, Montini E, Grompe M, Kozma SC, Thomas G. 2000. Proliferation, but not growth, blocked by conditional deletion of $40 S$ ribosomal protein S6. Science 288:2045-2047. doi: 10.1126/science.288.5473.2045.

Wade M, Li YC, Wahl GM. 2013. MDM2, MDMX and p53 in oncogenesis and cancer therapy. Nature Reviews Cancer 13:83-96. doi: 10.1038/nrc3430.

Wang X, Wang J, Jiang X. 2011. MdmX protein is essential for Mdm2 protein-mediated p53 polyubiquitination. The Journal of Biological Chemistry 286:23725-23734. doi: 10.1074/jbc.M110.213868.

Wang Y, Yang J, Zheng H, Tomasek GJ, Zhang P, McKeever PE, Lee EY, Zhu Y. 2009a. Expression of mutant p53 proteins implicates a lineage relationship between neural stem cells and malignant astrocytic glioma in a murine model. Cancer Cell 15:514-526. doi: 10.1016/j.ccr.2009.04.001.

Wang Z, Zheng M, Li Z, Li R, Jia L, Xiong X, Southall N, Wang S, Xia M, Austin CP, Zheng W, Xie Z, Sun Y. 2009b. Cardiac glycosides inhibit p53 synthesis by a mechanism relieved by Src or MAPK inhibition. Cancer Research 69:6556-6564. doi: 10.1158/0008-5472.CAN-09-0891.

Wu J, Chen Y, Lu LY, Wu Y, Paulsen MT, Ljungman M, Ferguson DO, Yu X. 2011. Chfr and RNF8 synergistically regulate ATM activation. Nature Structural \& Molecular Biology 18:761-768. doi: 10.1038/nsmb.2078.

Wu X, Bayle JH, Olson D, Levine AJ. 1993. The p53-mdm-2 autoregulatory feedback loop. Genes \& Development 7:1126-1132. doi: 10.1101/gad.7.7a.1126.

Xiong X, Zhao Y, He H, Sun Y. 2011. Ribosomal protein S27-like and S27 interplay with p53-MDM2 axis as a target, a substrate and a regulator. Oncogene 30:1798-1811. doi: 10.1038/onc.2010.569.

Yadavilli S, Mayo LD, Higgins M, Lain S, Hegde V, Deutsch WA. 2009. Ribosomal protein S3: a multi-functional protein that interacts with both p53 and MDM2 through its KH domain. DNA Repair 8:1215-1224. doi: 10.1016/ j.dnarep.2009.07.003.

Zhang X, Wang W, Wang H, Wang MH, Xu W, Zhang R. 2013. Identification of ribosomal protein S25 (RPS25)MDM2-p53 regulatory feedback loop. Oncogene 32:2782-2791. doi: 10.1038/onc.2012.289.

Zhang Y, Lu H. 2009. Signaling to p53: ribosomal proteins find their way. Cancer Cell 16:369-377. doi: 10.1016/ j.ccr.2009.09.024.

Zhang Y, Wang J, Yuan Y, Zhang W, Guan W, Wu Z, Jin C, Chen H, Zhang L, Yang X, He F. 2010. Negative regulation of HDM2 to attenuate p53 degradation by ribosomal protein L26. Nucleic Acids Research 38:6544-6554. doi: 10.1093/nar/gkq536.

Zhang Y, Wolf GW, Bhat K, Jin A, Allio T, Burkhart WA, Xiong Y. 2003. Ribosomal protein L11 negatively regulates oncoprotein MDM2 and mediates a p53-dependent ribosomal-stress checkpoint pathway. Molecular and Cellular Biology 23:8902-8912. doi: 10.1128/MCB.23.23.8902-8912.2003.

Zhou X, Hao Q, Liao J, Zhang Q, Lu H. 2013. Ribosomal protein S14 unties the MDM2-p53 loop upon ribosomal stress. Oncogene 32:388-396. doi: 10.1038/onc.2012.63.

Zhou X, Liao JM, Liao WJ, Lu H. 2012. Scission of the p53-MDM2 Loop by Ribosomal Proteins. Genes Cancer 3:298-310. doi: 10.1177/1947601912455200.

Zhu Y, Poyurovsky MV, Li Y, Biderman L, Stahl J, Jacq X, Prives C. 2009. Ribosomal protein S7 is both a regulator and a substrate of MDM2. Molecular Cell 35:316-326. doi: 10.1016/j.molcel.2009.07.014.

Zhu Y, Wang X, Goff SP, Gao G. 2012. Translational repression precedes and is required for ZAP-mediated mRNA decay. The EMBO Journal 31:4236-4246. doi: 10.1038/emboj.2012.271. 